\title{
Inventeurs en Révolution : la Société des inventions et découvertes
}

Inventors in Revolution : the Société des inventions et découvertes

\section{Christiane Demeulenaere-Douyère}

\section{CpenEdition}

\section{Journals}

Édition électronique

URL : http://journals.openedition.org/dht/483

DOI : $10.4000 /$ dht. 483

ISSN : $1775-4194$

Éditeur :

Centre d'histoire des techniques et de l'environnement du Cnam (CDHTE-Cnam), Société des élèves du CDHTE-Cnam

Édition imprimée

Date de publication : 31 mars 2009

Pagination : $19-45$

ISBN : 978-2-95-30779-3-3

ISSN : $0417-8726$

Référence électronique

Christiane Demeulenaere-Douyère, «Inventeurs en Révolution : la Société des inventions et découvertes », Documents pour l'histoire des techniques [En ligne], $17 \mid 1^{\mathrm{er}}$ semestre 2009, mis en ligne le 06 avril 2011, consulté le 10 décembre 2020. URL : http://journals.openedition.org/dht/483 ; DOI : https://doi.org/10.4000/dht.483

(c) Tous droits réservés 


\title{
Inventeurs en Révolution : la Société des inventions et découvertes*
}

\author{
Christiane Demeulenaere-Douyère \\ Archives nationales, Paris \\ CDHTE-Cnam
}

\begin{abstract}
"Dès les premiers moments de la Révolution, plusieurs artistes se réunirent et résolurent de tirer les arts et métiers de l'état d'oubli et d'oppression dans lesquels ils gémissoient depuis Louis XIV ॥ Journal des sciences, arts et métiers, nº 1, 22 janvier 1792
\end{abstract}

\begin{abstract}
RÉSUMÉ
Avec la loi du 21 août 1790 autorisant les sociétés libres, certains « artistes-inventeurs » se regroupent au sein de la Société des inventions et découvertes dès l'été 1790 pour obtenir des mesures garantissant leur propriété sur leurs inventions.

La documentation existante sur la Société des inventions et découvertes, même si elle est lacunaire, permet de la saisir à quatre moments clés de son existence : en 1791, lors du vote des lois protectrices de l'invention, puis en 1793, lorsqu'elle se met au service de la Patrie en danger, en l'an VI [1798] avec un projet de règlement particulièrement novateur, et enfin à son déclin, en 1810-1811.

Elle permet aussi de mettre en évidence certains points forts de la Société ; elle montre notamment que, par la capacité de ses membres à s'organiser, elle a jové un rôle de premier plan dans l'adoption, en France, de la législation sur les brevets d'invention et, au-delà, dans l'émergence dans le débat public des gens de métier par une autre voie que la voie politique bien connue des sociétés populaires, et leur volonté de prendre en mains collectivement leurs propres intérêts.
\end{abstract}

Résumés et mots clés en anglais sont regroupés en fin de volume, accompagnés des mots clés français

En 1790-1791, l'activité législative de l'assemblée constituante est en partie centrée autour de la question des inventions et des inventeurs. Sont alors adoptées des mesures qui reconnaissent et garantissent la propriété de ceux-ci sur leurs découvertes'. Ces mesures constituent une réelle avancée qui répond aux vœux des principaux intéressés et à laquelle euxmêmes n'ont pas été étrangers.

À la faveur du processus révolutionnaire qui ouvre des voies nouvelles d'expression et de publicité et fournit des outils démocratiques comme le droit de s'assembler en sociétés et celui d'adresser des pétitions à la représentation nationale ${ }^{2}$, on voit des citoyens s'organiser en « sociétés libres » pour investir

1 Gérard Emptoz et Valérie Marchal, Aux sources de la propriété industrielle. Guide des archives de I'INPI, Paris, INPI, 2002, pp. 32-41 et 203-207.

2 L'individu face au pouvoir : les pétitions aux assemblées parlementaires, Revue administrative, nº spécial 2008. l'espace public. Profitant eux aussi de la loi du 21 août $1790^{3}$, certains « artistes-inventeurs », ainsi qu'ils se désignent eux-mêmes, se regroupent en société de fait dès l'été 1790 ; quelques mois plus tard, ils s'érigeront officiellement en Société libre des inventions et découvertes ${ }^{4}$. Alors que les sociétés et clubs créés à la faveur de cette loi exercent leur action plutôt dans le domaine politique ou dans celui de l'instruction ou de l'entraide, cette société d'inventeurs s'inscrit dans

3 Cette loi reconnaît aux citoyens "le droit de s'assembler paisiblement et de former entre eux des sociétés libres à la charge d'observer les lois qui régissent tous les citoyens ", Jean-Claude Bardout, L'histoire étonnante de la loi de 1901. Le droit d'association avant et après Pierre Waldeck-Rousseau, Lyon, Éd. Juris Service, 2001, pp. 85 et suiv.

4 Le rôle des sociétés d'inventeurs a été souligné par Roger Hahn, L'anatomie d'une institution scientifique : l'Académie des sciences de Paris, 1666-1803, Bruxelles-Paris, Éd. des archives contemporaines, 1993, pp. 263 et suiv.

*Avec mes vifs remerciements aux collègues dont les suggestions ont enrichi ma réflexion sur les questions abordées ici, et particulièrement Patrice Bret, Gabriel Galvez-Behar, Valérie Nègre et Liliane Pérez. 


\section{Inventeurs en Révolution}

un registre original, celui de la défense des intérêts moraux et économiques d'une communauté socioprofessionnelle, aux contours mal définis, mais tendue vers un but commun à atteindre.

Faute de disposer des archives de la Société des inventions et découvertes ${ }^{5}$, qui permettraient d'en reconstituer avec précision l'histoire, nous proposons ici d'essayer de la saisir à quatre moments clés de son existence, pour lesquels on dispose d'une documentation : en 1791, lors du vote des lois protectrices de l'invention, puis en 1793, lorsqu'elle se met au service de la Patrie en danger, en l'an vı [1798] avec un projet de règlement particulièrement novateur, et enfin à son déclin, en 1810-18116.

\section{Les inventeurs et le législateur (1791)}

Si les privilèges des inventeurs ne sont pas concernés par le grand ménage de la nuit du 4 août 1789, si la déclaration des droits de l'homme consacre la propriété, on enregistre néanmoins dans les faits une certaine remise en question des pratiques anciennes ${ }^{7}$. Ainsi, le $1^{\text {er }}$ septembre 1789, examinant la requête d'un gentilhomme anglais visant à obtenir un privilège exclusif pour établir en France une manufacture pour peindre et imprimer sur verre, porcelaine et faïence, le Bureau du commerce rend une décision favorable sur le principe, tout en précisant qu'« on surseoira cependant à la concession du privilège demandé attendu que l'Assemblée nationale s'occupe de la question des privilèges exclusifs $1{ }^{8}$.

5 On dispose de quelques procès-verbaux de séances (27 janvier et 2 février 1792, BnF, ms. fr. 8045, catalogué à tort comme relatif au «Bureau consultatif des arts »), et d'un extrait de celui du ler août 1793 (Arch. Musée des arts et métiers, NS5 [Reth]/1, pièce 4).

6 Néanmoins, la Société semble se perpétuer plus avant dans le $x x^{e}$ siècle. Un portrait lithographié de l'horloger Robert Robin, édité après 1823, signale son appartenance à « la Société nationale des inventions et découvertes de France " (publié dans Tardy, Dictionnaire des horlogers français, Paris, 1971, t. 2) ; à cette date, ce titre doit encore être signifiant pour le public.

7 La Révolution se montre très respectueuse des privilèges accordés par l'Ancien Régime : I'article 17 de la loi du 7 janvier 1791, tout en respectant les privilèges exclusifs précédemment accordés pour inventions et découvertes jusqu'à leur terme, donne aux bénéficiaires de privilèges accordés par simples arrêts du Conseil ou lettres patentes non enregistrées la faculté de les convertir sans frais en brevets d'invention pour le temps qui leur reste à courir. Pour l'avenir, il est clair que, dans l'esprit du législateur, la procédure des brevets d'invention se substitue pleinement à celle des privilèges.

8 Pierre Bonassieux et Eugène Lelong, Conseil de commerce et Bureau du commerce, 1700-1791, Inventaire analytique
L'année 1790 est le cadre de beaucoup d'effervescence et d'une importante réflexion autour de questions comme l'utilité de l'invention, sa propriété, sa rétribution... D'autant que, le 10 juillet 1790, les pensions royales sont remplacées par des récompenses offertes aux individus qui apportent à la nation des contributions décisives 9 . Cette mesure concerne aussi les hommes de lettres, les savants et les artistes; or des inventeurs figuraient de longue date parmi les pensionnés du roi.

Ces circonstances conduisent des inventeurs à s'organiser pour veiller collectivement à une meilleure protection de leurs intérêts catégoriels. Eł c'est à l'occasion du débat législatif qui entoure le vote des lois protectrices de l'invention en 1791 que l'on voit la Société des inventions et découvertes se manifester publiquement pour la première fois.

Son annuaire pour 1810 donne un bref aperçu des conditions dans lesquelles elle s'introduit dans ce débat que, d'ailleurs, grâce à sa parfaite maîtrise du lobbying ${ }^{10}$, elle suscite et entretient avec habileté :

« [...] quelques Artistes et Inventeurs qui, dans le courant du mois d'août 1790, se réunirent pour solliciter de l'Assemblée nationale quelques décrets favorables aux propriétés industrielles, et une législation à peu près conforme à celle des Patentes anglaise 1 .

Sa première démarche officielle date donc d'août 1790 : elle adresse alors au Comité d'agriculture et de commerce de la Constituante une « pétition motivée dans laquelle [elle] sollicit[e] une législation conforme à celle des patentes anglaises " ", et réclame la création « d'un pareil établissement [un système analogue aux patentes anglaises], non seulement en prouvant qu'il étoit généralement désiré par les Artistes de la capitale, par la plupart des chambres et des députés du Commerce, mais encore en offrant un parallèle des effets avantageux de la protection accordée en Angleterre aux Inventeurs depuis 1623 [...] avec ceux tous contraires produits pendant le même temps, soit par la négligence du gouvernement français, soit par

des procès-verbaux, Paris, Archives nationales, 1900, pp. 475 , col. b, 1er septembre 1789

9 Archives parlementaires, t. 17, loi du 3 août 1790.

10 Christiane Demeulenaere-Douyère, « Les pétitions et leur rôle dans le vote des lois sur l'invention en 1791 ॥, dans L'individu face au pouvoir..., op. cit. note 2, p. 61-69.

11 Cette pétition, dont on n'a pas l'original, est connue par la « Respectueuse pétition des artistes inventeurs » à l'Assemblée nationale qui l'évoque amplement, Archives parlementaires, t. 24, p. 642 (7 avril 1791). 


\section{Christiane Demeulenaere-Douyère}

les rebuts, entraves ou dégoûts sont les Inventeurs étoient sans cesse abreuvés $11^{12}$.

Au Comité d'agriculture et de commerce, cette pétition rencontre l'intérêt du chevalier de Boufflers ${ }^{13}$, député de la noblesse de Nancy aux États généraux puis à la Constituante. Son passé de militaire bel esprit ne semblait guère le disposer à se faire le porte-parole des inventeurs, mais le désarroi de ces derniers sait toucher les sentiments philanthropiques de cet homme des Lumières:

" les Artistes trouvèrent en lui un zélé protecteur qui voulut bien se charger de tout le travail nécessaire, et qui, par suite des renseignements qui lui furent fournis et des discussions qui eurent lieu, fit adopter le 30 [décembre] 1790, à l'Assemblée nationale, un décret ${ }^{14}$ qui consacra la propriété des Inventeurs, à la suite d'un rapport dans lequel, après avoir fait un détail aussi pathétique que vrai de tous les désagréments éprouvés jusqu'alors par la plupart des Inventeurs, il établit victorieusement leurs droits et fit sentir la nécessité que le Gouvernement les maintienne et protège $\|{ }^{15}$.

Le commentaire qui suit - ce rapport « devroit être le Manuel des Inventeurs, puisqu'ils pourroient dans ce rapport étudier parfaitement l'esprit des lois sur les brevets d'Invention »-montre clairement, et avec une

12 Annuaire de la Société des inventions et découvertes pour l'année 1810, premier cahier, Paris, Imprimerie de P. N. Rougeron, 1810, pp. 1-2. Gabriel Galvez-Behar (La République des inventeurs. Propriété et organisation de l'innovation en France (1791-1922), Rennes, PUR, 2008, p. 22) souligne justement que la question du droit des inventeurs se pose en même temps que celle des auteurs dramatiques et des artistes; cette concomitance montre combien la question de la protection des droits des créateurs sur leurs créations est alors cruciale.

13 Stanislas-Jean de Boufflers (1738-1815). Chevalier de Malte, il prend part à plusieurs campagnes militaires et fait de nombreux voyages. Nommé gouverneur du Sénégal et de Gorée, en 1786-1787, il se révèle un administrateur efficace et humaniste. Reçu à l'Académie française en 1788, il est envoyé aux Éłats Généraux par la noblesse du bailliage de Nancy. Siégeant ensuite à la Constituante, il est un des fondateurs du club des Impartiaux et s'occupe de la protection de l'industrie et de l'invention. Modéré et hostile à la Constitution civile du clergé, il émigre en Prusse dès octobre 1791 ; il obtient de rentrer en France en 1800 (Dictionnaire de biographie française, $t$. 6).

14 Archives parlementaires, †. 21, pp. 721-732 ; promulgué le 7 janvier 1791 comme « loi relative aux découvertes utiles et aux moyens d'en assurer la propriété à ceux qui seront reconnus en être les auteurs $).$

15 Annuaire [...] pour l'année 1810, op. cit. note 11, p. 2. certaine candeur, combien ces artistes-inventeurs se sont investis personnellement dans la préparation du rapport du chevalier de Boufflers, lui fournissant une "série méthodique de mémoires " ${ }^{16}$, en fait de véritables études historiques, comparatives et bien documentées sur l'usage des patentes d'invention et les privilèges exclusifs en Angleterre, aux États-Unis et en France, dont Boufflers a pu nourrir ses rapports et son projet de loi sur « les encouragements et privilèges à accorder aux inventeurs de machines et de découvertes industrielles $॥$. C'est dire combien les membres de la Société des inventions et découvertes se reconnaissent la paternité de la loi du 7 janvier 1791 qui consacre la propriété de chacun sur les découvertes et inventions dont il est l'auteur et lui en garantit la jouissance par un simple dépôt, sans aucun examen préalable.

La loi est votée, mais il reste à la faire entrer en application, et c'est ce à quoi les artistes-inventeurs vont s'employer très activement. C'est dans ce contexte que ce qui n'est encore qu'une association informelle s'affermit en se transformant en Société nationale des inventions et découvertes, de manière hautement symbolique, le 7 janvier 1791, soit le jour même de la promulgation de la loi. L'acte de constitution initial est signé de quarante-sept noms ${ }^{17}$. Conformément à la mission qu'elle se donne de «suivre toujours les démarches nécessaires pour faire adopter les mesures les plus propres à protéger, à encourager et activer l'industrie nationale ${ }^{18}$, dont les intérêts rejoignent ceux de ses sociétaires, elle va intensifier et maintenir sans faiblir sa pression sur la Constituante et ses comités, en multipliant motions de remerciements, députations et pétitions.

Le 31 janvier 1791, après avoir rédigé des remerciements au Comité d'agriculture et de commerce, elle lui envoie une députation chargée de présenter « une pétition tendant $1^{\circ}$ à ce que l'Assemblée nationale nomme un de ses membres comme commissaire à l'effet de diriger l'établissement du bureau des pa-

16 « Respectueuse pétition des artistes inventeurs ॥, Archives parlementaires, †. 24, p. 642 (7 avril 1791).

17 Signataires de l'acte de constitution de la SID, le 7 janvier 1791 : Genard, Michel, Cardon, Vegence, de Monchaux, de Trouville, L'Homont, de Sutières, Lachiche, Smithz, Georget, d'Yvernois, Janety, Guyot, Mégnié, Fortin, Cressot, Le Rolsbergherr de Vausenville, Charpentier, Hérisson, Robillard, Mossi, Lenoir, Le Joyand, l'abbé de Mandres, Chrétien, Richer, Antoine Teste, Pierre Doneaud, Merklein, Frédéric Hildebrand, Denemet, Bonnemain, Raimbault, Hulot, Marion, Delaplace, Jeuneux, Grégoire, Leturc, Leconte, Dupont, Baradelle, Putois, Lange, de Servières (président provisoire), Le Vayer (secrétaire provisoire) (Annuaire [...] pour l'année 1810, op. cit. note 11, p. 4). $18 \mathrm{lbid}$. 


\section{Inventeurs en Révolution}

tentes ; $2^{\circ}$ à ce que la direction de ce bureau soit confiée à $M$. de Servières et que pour cet effet il soit désigné et recommandé particulièrement au pouvoir exécutif ॥. Le comité autorise son président à appuyer la demande de la Société des inventions et découvertes " concernant $M$. de Servières " ${ }^{19}$.

Pour les artistes-inventeurs, il y a une véritable urgence : ils réclament la mise en place sans délai du bureau central chargé d'expédier les patentes d'invention qui est prévu par la loi, et ne prétendent à rien moins que le contrôler, par l'intermédiaire de leur président, Servières, dont ils demandent la nomination comme directeur de ce bureau.

La Société des inventions et découvertes n'en demeure pas là. Une semaine plus tard, le 8 février 1791, c'est à la Constituante qu'elle envoie une nouvelle députation, dont Servières est l'orateur :

" Réunis enfin par une joie commune, par l'enthousiasme de nos recherches et de nos travaux pour les biens et les besoins mutuels qui enchaînent tous les arts entre eux, et surtout par cette fraternité civique, avant-goût délicieux des fruits de la liberté, il nous a semblé qu'elle nous suggérait un moyen de réaliser quelques-unes de vos grandes pensées et d'accorder nos efforts pour les progrès de l'industrie $\|{ }^{20}$

II s'agit alors de faire part officiellement de la création récente de la Société des inventions et découvertes. Le président de l'Assemblée constituante en prend acte et lui rend hommage en quelques mots :

"Une société, consacrée à favoriser les découvertes, acquitte une dette de la société entière ; l'art de créer le génie n'est peut-être que l'art de le seconder; et la Société des inventions et découvertes est déjà une invention d'autant plus utile qu'elle deviendra la source de beaucoup d'autres 11.

19 Fernand Gerbaux et Charles Schmidt, Procès-verbaux des Comités d'agriculture et de commerce de la Constituante, de la Législative et de la Convention, Collection de documents inédits sur l'histoire économique de la Révolution française, Paris, Imprimerie nationale, 1906-1910 et 1937, 5 vol., t. 2, p. 16. 20 Le texte original de l'adresse est conservé sous la cote AN Paris, C/54, §541; il est signé de Servières, président de la SID, Levayer, secrétaire, Baradelle, Jeuneux, D'Ivernois, La Chiche, Mercklein, De Mouchaux, Grégoire, Boze, Lainé, Bonnot, Guyot, Teillard, L'Ange, Ruelle, Chrétien et Menneville; les Archives parlementaires (t. 23, p. 54) en donnent une version un peu altérée.
Puis, le 11 février 1791, une nouvelle députation de la Société, toujours emmenée par Servières, se présente au Comité d'agriculture et de commerce

" pour l'informer du travail théorique et pratique dont la Société s'occupe afin de donner un plan relatif aux moyens de prévenir les malheureux accidents auxquelles les voitures publiques ne sont que trop sujettes et le prier en conséquence d'inviter M. le Contrôleur général, dans l'adjudication qu'il doit faire samedi matin du bail des messageries, à joindre au cahier des charges la condition que les adjudicataires seront tenus de choisir, parmi les moyens que la Société des inventions et découvertes leur proposera, ceux que l'on jugera les plus propres à remplir ce grand objet de sûreté publique $॥$.

Le Comité, séduit, applaudit à ces propositions ${ }^{21}$.

Le souci primordial de la Société des inventions et découvertes est d'occuper la tribune et tous les moyens sont bons. Cette inquiétude et cet activisme sont largement justifiés par les circonstances. En effet, on est alors en pleine préparation du projet de règlement pour l'exécution de la loi du 7 janvier 1791, dans un contexte, semble-t-il, de forte contestation, beaucoup plus houleux que celui qui a entouré le vote de la loi elle-même. II s'agit d'organiser le Directoire central des inventions, de définir ses compétences vis-à-vis des directoires des départements, et d'établir le mode d'obtention, de jouissance et de cession des brevets. Le projet de règlement, présenté à l'Assemblée par Boufflers, toujours lui, au nom du Comité d'agriculture et de commerce, le 29 mars 1791, est discuté âprement ${ }^{22}$. Des arguments forts lui sont opposés ${ }^{23}$. Devant l'impasse, on menace de renvoyer le vote du règlement, et avec lui l'application de l'ensemble de la loi sur les brevets, à la législature suivante. Or il est capital pour les inventeurs que le texte soit voté au plus vite. Pour débloquer la situation, les inventeurs mettent alors en œuvre une stratégie de « pilonnage pétitionnaire ॥. Le 8 avril 1791, la Constituante entend la réponse de Boufflers aux diverses objections ${ }^{24}$. La veille, pour l'appuyer, la Société des inventions et découver-

21 Gerbaux et Schmidt, Procès-verbaux des Comités d'agriculture et de commerce, op. cit. note 19, t. 2, p. 47.

22 Archives parlementaires, t. 24, p. 456.

23 R. Hahn souligne notamment l'opposition déterminée d'un député, par ailleurs membre associé de l'Académie des sciences, Dionis du Séjour, qui s'inquiète de l'absence de tout examen préalable à la délivrance du brevet (L'anatomie d'une institution scientifique, op. cit. note 4, pp. 267-268).

24 Archives parlementaires, †. 24, pp. 636-641. 


\section{Christiane Demeulenaere-Douyère}

tes a porté à l'assemblée une « respectueuse pétition des artistes inventeurs $॥$ :

Ils « portent leurs espérances, manifestent les craintes dont ils sont agités et [...] exposent une suite de faits, bien propres à dissiper les nuages que I'on cherche en vain à répandre sur leurs imprescriptibles droits, puisqu'ils ne les tiennent que de la nature $\|{ }^{25}$.

Et ils demandent l'adoption du règlement dans les meilleurs délais.

La Société des inventions et découvertes reprend l'offensive trois jours plus tard: le 11 avril 179126, le Comité d'agriculture et de commerce reçoit un mémoire réclamant une nouvelle fois l'organisation de l'établissement chargé d'expédier les brevets d'invention. II faut noter que les inventeurs recherchent l'appui de l'opinion en donnant une audience plus large à leurs démarches : elles sont relayées par la Chronique de Paris et l'adresse est imprimée en fascicule, sans doute pour en faire une large diffusion.

Finalement, ces mesures sont votées, pratiquement sans débat, le 14 mai 1791 (promulguées le 25 mai 1791) et le Directoire des brevets entre en fonctions dès les premiers jours de juillet 1791. Et, comme le souhaitait la Société des inventions et découvertes, c'est son président, Servières, qui est mis à sa tête. Pour la société d'inventeurs, cette nomination, qui est très certainement à mettre au compte de son action insistante et habile de lobbying, est un immense succès.

En complément des lois de janvier et de mai 1791, la loi du 12 septembre-16 octobre 1791 règle l'organisation et le fonctionnement du Bureau de consultation des arts et métiers. L'enjeu, une nouvelle fois, est de première importance pour les artistes-inventeurs puisque cette nouvelle instance a pour mission de conseiller le gouvernement dans l'attribution des récompenses nationales créées par le décret du 22 août $1790^{27}$. Ce bureau reprend en grande partie

25 Ibid., t. 24, pp. 641-644 ; la pétition est du 2 avril 1791. $26 \mathrm{BnF}, \mathrm{Vp}-8296$, « Adresse des artistes-inventeurs au Comité d'agriculture et de commerce ", signalée dans Gerbaux et Schmidt, Procès-verbaux des Comités d'agriculture et de commerce, op. cit. note 19, t. 2, p. 46.

27 II s'agit de l'attribution d'aides en espèces à des artistes en raison de "leurs découvertes et leurs travaux dans les arts utiles "; à noter toutefois que la demande et l'obtention d'un brevet d'invention interdisent de prétendre à une récompense nationale, qui ne peut être accordée qu'à un inventeur faisant don de son invention à la nation ; le Bureau de consultation agit ici davantage comme un bureau d'assistance à l'invention que comme un organe de validation la fonction d'évaluation et de validation de l'invention qu'exerçait auparavant l'Académie royale des sciences, selon des procédures d'ailleurs assez semblables (par exemple, désignation d'un commissaire chargé de l'examen du dossier).

Sans doute faut-il voir dans l'élaboration de ces mesures l'influence de la Société des inventions et découvertes, comme le confirme d'ailleurs la lettre du 7 août 1791 que Servières adresse au ministre de I'Intérieur :

"Ce matin, au moment où je me disposais à vous aller soumettre un petit travail, M. le Chevalier de Boufflers est survenu et il a désiré que je conférasse avec lui sur le rapport qu'il doit faire au premier jour à l'Assemblée nationale touchant les récompenses destinées aux artistes. Cet entretien s'est prolongé jusqu'à trois heures et demie $1{ }^{28}$.

E† là encore, la Société tire les bénéfices de son investissement. C'est au travail réalisé en lien étroit avec Boufflers et aussi aux relations d'estime qui semblent s'instaurer entre Servières et lui, que la Société des inventions et découvertes doit d'être avantageusement représentée au Bureau de consultation des arts et métiers. Si la moitié des trente places qui le composent revient à l'Académie des sciences - qui perd le monopole même si elle reste majoritaire ${ }^{29}$, en face siège « pareil nombre d'hommes instruits dans les différents genres d'industries $॥$, issus de diverses sociétés scientifiques et techniques ${ }^{30}$. Parmi celles-ci, la Société des inventions et découvertes bénéficie d'une représentation exceptionnelle, avec quatre représentants ${ }^{31}$, alors que les autres sociétés ne disposent que d'un siège ou de deux tout au plus.

de l'invention ; Dominique de Place, « Le Bureau de consultation pour les Arts, Paris, 1791-1796 1, History and technology, 5, 1988, pp. 139-178, particulièrement pp. 139-140.

28 AN Paris, F/17/1136, pp. 90-200, correspondance de Servières, directeur des inventions, 10 juillet 1791-17 août 1792, ici p. 95. 29 Contrairement au rapport initial de Boufflers qui prévoyait une égale représentation de chaque société savante au Bureau de consultation ; mais Boufflers et le Comité d'agriculture et de commerce durent reculer devant l'intrigue académique, Journal des sciences, arts et métiers, 1792, n 1, p. 5. 30 La Faculté de médecine, l'Académie de chirurgie, la Société de médecine, la Société royale d'agriculture, la Société d'histoire naturelle, la Société des Annales de chimie, la Société philomathique, la Société du Point central, le Lycée des arts, la Société des artistes réunis, et la Société des inventions et découvertes.

31 La SID y est représentée par son président, Servières, et trois autres membres, Trouville, Leblanc et Guiraud. 


\section{Inventeurs en Révolution}

Cette nouvelle victoire des artistes-inventeurs de la Société des inventions et découvertes est une fois encore le résultat de leur ténacité et de la pression qu'ils ont été en mesure d'exercer sur les acteurs politiques. Une pression dont le chevalier de Boufflers semble parfois un peu victime:

" Je viens d'éprouver une petite interruption de quatre jours pendant lesquels messieurs les artistes, que Dieu confonde !, n'ont cessé de me molester, au point que je suis obligé de les fuir comme les créanciers les plus importuns. Je suis quelquefois tenté d'abandonner la partie ; mais le spectacle de leur misère me touche, et ma passion redouble en pensant que sûrement personne d'autre ne se chargerait de leur cause, surtout si l'on savait la manière véritablement odieuse dont ils la sollicitent. Je me vois comme ces malheureux condamnés que, dans quelques parties de l'Italie, on frotte de miel depuis les pieds jusqu'à la tête, et que ensuite on expose aux mouches sous les morsures desquelles ils succombent, au bout de deux jours, dans des tortures et des convulsions horribles.

Je voudrais quelquefois, après les avoir vu déchiqueter mes matinées, donner au moins la soirée à mes affaires [...] ; mais nos séances et nos comités m'enlèvent encore ce temps-là et, quand je reviens vers dix ou onze heures, avec le projet d'écrire, j'éprouve alors un nouveau supplice, celui de ne pouvoir plus du tout écrire aux lumières $\|{ }^{32}$.

Toutefois, la prééminence encore réelle de l'Académie des sciences au sein du Bureau de consultation des arts et métiers est ressentie comme une trahison dans la communauté des artistes-inventeurs. Le 2 décembre 1791, le Comité du commerce de la Législative renvoie en commission une pétition d'artistes, datée du 16 octobre précédent ${ }^{33}$, rédigée par des " artistes en tous genres, composant les Sociétés de la Commune des arts, des exposants au salon du Louvre, des inventions et découvertes, des Neuf-Sœurs, du Point central des arts et métiers, et d'autres artistes, tous réunis fraternellement $॥$. Ces sociétés s'unissent pour réclamer l'augmentation des secours alloués aux artistes et protestent contre la composition du Bureau de consultation des arts et métiers telle qu'elle est organisée par la loi du 27 septembre 1791. Elles deman-

32 Lettre de Boufflers à Mme de Sabran, fin septembre 1791, cité par Pierre de Croze, Le Chevalier de Boufflers et la Comtesse de Sabran (1788-1792), Paris, Calmann Lévy, 1894, pp. 279-280. 33 Publiée dans le Journal des sciences, arts et métiers, $\mathrm{n}^{\circ} 1$, 22 janvier 1792, et sous forme de tirés à part, dont AN Paris, $A D / V I I / 29$, pièce 3 , et $B n F, V p-3673,8302$ et 8303. dent, en vain, qu'on en revienne au projet initial du Comité d'agriculture et de commerce de la Constituante, que ce bureau comporte soixante membres tant est immense la tâche qui l'attend, et que les académies ne puissent « concourir à cette nomination que comme les autres sociétés d'artistes ${ }^{34}$.

Grâce à ses efforts assidus, à un certain sens politique et à son habileté à faire pression sur l'Assemblée, la Société des inventions et découvertes a donc obtenu satisfaction en un temps record. Elle a réussi à faire adopter le brevet d'invention. En investissant massivement les institutions nouvelles qu'elle a contribué à faire créer, elle s'est assuré un véritable leadership de fait sur la communauté des artistes-inventeurs : son président Servières est directeur des brevets de juillet 1791 à octobre 1792 et elle dispose de quatre représentants, dont son président, au Bureau de consultation des arts et métiers. La maîtrise de ces postes, notamment au Bureau de consultation, en lui permettant d'influer sur l'attribution des récompenses en argent prévues par la loi, peut lui permettre de se faire bien des obligés parmi les inventeurs, dont la survie économique dépend souvent de ces aides.

Sil'année 1791 peut s'achever pour elle sur un bulletin de victoire, la suite va se révéler plus difficile.

\section{Les inventeurs et la Patrie en danger (1793)}

Le 23 brumaire an ॥ [13 novembre 1793], le Comité de Salut public publie une circulaire demandant aux sociétés populaires «la liste des citoyens qui sont les plus propres à remplir les fonctions publiques dans tous les genres $"{ }^{35}$. La Société des inventions et découvertes saisit cette occasion pour tenter de revenir dans le jeu public.

Les Archives nationales ont acquis le manuscrit comportant les offres de services que font alors ses membres ${ }^{36}$. Ce document, dressé en tableau grand format et soigneusement présenté et calligraphié, fournit la liste des cinquante membres qui la composent à cette date. Pour chacun d'entre eux, il apporte des informations précises : ses nom et prénom(s), son âge, son lieu de naissance, son domicile (rue et sec-

34 Gerbaux et Schmidt, Procès-verbaux des Comités d'agriculture et de commerce, op. cit. note 19, t. 2, p. 636, note 2. Le 4 décembre 1791, la Législative reçoit une pétition « des artistes composant les sociétés de la Commune des Arts" - est-ce une nouvelle pétition ou la même ? - qui reprend les mêmes revendications, James Guillaume, Procès-verbaux du Comité d'instruction publique de l'assemblée législative, Paris, Imprimerie nationale, 1899, pp. 49-50.

35 F. A. Aulard, Recueil des actes du Comité de Salut public..., t. 8, Paris, Imprimerie nationale, 1895, pp. 392-394. 36 AN Paris, $A B / x \mid x / 5188$, publié in extenso en annexe 1. 


\section{Christiane Demeulenaere-Douyère}

tion) et son «état». Dans une rubrique «Travaux dans les arts et sciences ॥, il précise les travaux déjà réalisés par chacun, mettant en valeur ceux qui touchent à l'intérêt public et qui sont le plus susceptibles d'intéresser le Comité de salut public (machines diverses, grue, paratonnerres, pompes hydrauliques, machines contre le méphitisme...) ; enfin, une rubrique spéciale concerne les « places publiques qu'ils peuvent remplir » et une dernière rubrique « Observations » apporte des compléments d'information.

Ce tableau insiste particulièrement sur les emplois publics ou d'intérêt général que certains membres ont occupés ou occupent encore : ainsi, pour François Cointeraux, il est précisé qu'il est " ancien expert et arpenteur juré $\|$; pour Michel Jean Jérôme Dizé, que «sa manufacture [...] est dans la plus grande activité pour le service des armées »; pour Gabriel Feuillet, qu'« il est l'un des chefs d'attelier instituteurs d'élèves en arquebuserie à la manufacture d'armes ") ; pour Nicolas Fortin, qu'u il s'est occupé à la construction des étalons des nouvelles mesures de capacité "); pour Adam Frédéric Gass, qu'« il a été employé à la manufacture de Sèvres. Occupé en ce moment par la Commission des poids \& mesures pour traiter le platine en grand »; Jean Henry Divernois est " juré d'accusation au tribunal criminel du département de Paris $"$; quant à Lachiche, il « vient d'être appellé par le ministre de la Guerre au Comité des fortifications », etc.

Comme s'il s'agissait de donner une image militante de la Société des inventions et découvertes, en montrant combien ses membres ont déjà engagé leurs talents au service de la République. Face à la Société du Point central des arts et métiers qui se proclame en 1793 « composée de tous artistes, vrais sans-culottes $1{ }^{37}$ et qui est proche du Cercle social aux actions duquel elle s'associe souvent ${ }^{38}$, sans doute pâtit-elle d'une image trop modérée, pas assez engagée en politique, qu'il convient de corriger.

Effectivement, en rupture avec sa stratégie de 1791, la Société des inventions et découvertes tient à afficher, en ces temps troublés d'agitation populaire, une certaine distance vis-à-vis de l'action politique directe qu'elle renvoie aux sociétés patriotiques dont elle veut se démarquer nettement. Ainsi, en janvier 1792, face à une « députation de la société des Amis des droits de l'homme et du citoyen relativement à la rédaction en commun par les diverses sociétés pa-

37 Archives parlementaires, t. 79, p. 256 ; la Société du Point central des arts et métiers a été créée en mai 1791.

38 Raymonde Monnier, L'espace politique démocratique, Paris, Kimé, 1994, p. 50 ; elle compte le Point central des arts et métiers comme une « société fraternelle », mais ignore la SID (p. 46). triotiques d'une affiche pour l'instruction du peuple ॥, elle précise que

" son institution [est] spécialement le progrès des arts et non les affaires publiques [...]. En regrettant de ne pouvoir collectivement s'occuper des objets proposés par la députation, elle a considéré d'un autre côté que beaucoup de ses membres appartenant à diverses sociétés patriotiques, ils pourraient par là contribuer au bien public que se proposent de faite nos frères des Amis des droits de l'homme et du citoyens $1{ }^{39}$.

Et, le 2 février 1792, son président répond à une députation du Club des Cordeliers que « quoique la Société s'occupe plus particulièrement des objets des arts, il pensait que la Société prendrait leur demande en grande considération $1{ }^{40}$.

Cette prudence - peut-être même méfiance - à l'égard de la chose politique est confirmée par le constat que ses membres, à l'exception d'Alexandre Ruelle ${ }^{41}$ ou peut-être de Claude Fournier ${ }^{42}$, ne semblent guère avoir joué de rôle politique déclaré, notamment dans les sections parisiennes ${ }^{43}$.

En revanche, l'aggravation de la situation internationale aidant, elle n'a pas manqué de mettre au service du gouvernement les compétences de ses sociétaires, en espérant sans doute en tirer des subventions ou des commandes publiques. En février 1793, elle a présenté une Pétition sur des moyens de défense de la Patrie (fig. 1) ) $^{44}$ dans laquelle elle mettait à la disposition de la Convention, dans un texte très empreint de phraséologie révolutionnaire («tyrans coalisés », " peuple généreux », " ennemis de la République $॥ . .$.$) , les travaux de ses membres sur des objets$ touchant à l'armement et aux fournitures pour les troupes (tentes, voitures, vêtements militaires...). Plus tard,

39 BnF, ms. fr. 8045, p. 8, « Extrait du procès-verbal de la Société des inventions et découvertes du vendredi 27 janvier $1792 \%$.

40 lbid., p. 7, séance du 2 février 1792.

41 II est trésorier du comité révolutionnaire de la Section de l'Observatoire, Albert Soboul et Raymonde Monnier, Répertoire du personnel sectionnaire parisien en I'an ॥, Paris, Publications de la Sorbonne, 1985, p. 508.

42 Très engagé dans les événements qui ont entouré la prise de la Bastille, le 14 juillet 1789, et la marche sur Versailles du 5 octobre 1789, Dictionnaire de biographie française, notice « Fournier (Claude) "), sous réserve qu'il n'agisse pas d'un homonyme.

43 Soboul et Monnier, Répertoire du personnel sectionnaire parisien en l'an ॥, op. cit. note 41, passim

44 Pétition sur des moyens de défense de la Patrie présentée à la Convention nationale par la Société des inventions et découvertes le dimanche 17 février 1793 (an II), Paris, Imprimerie du Cercle social, 4 rue du Théâtre-français, s.d. 


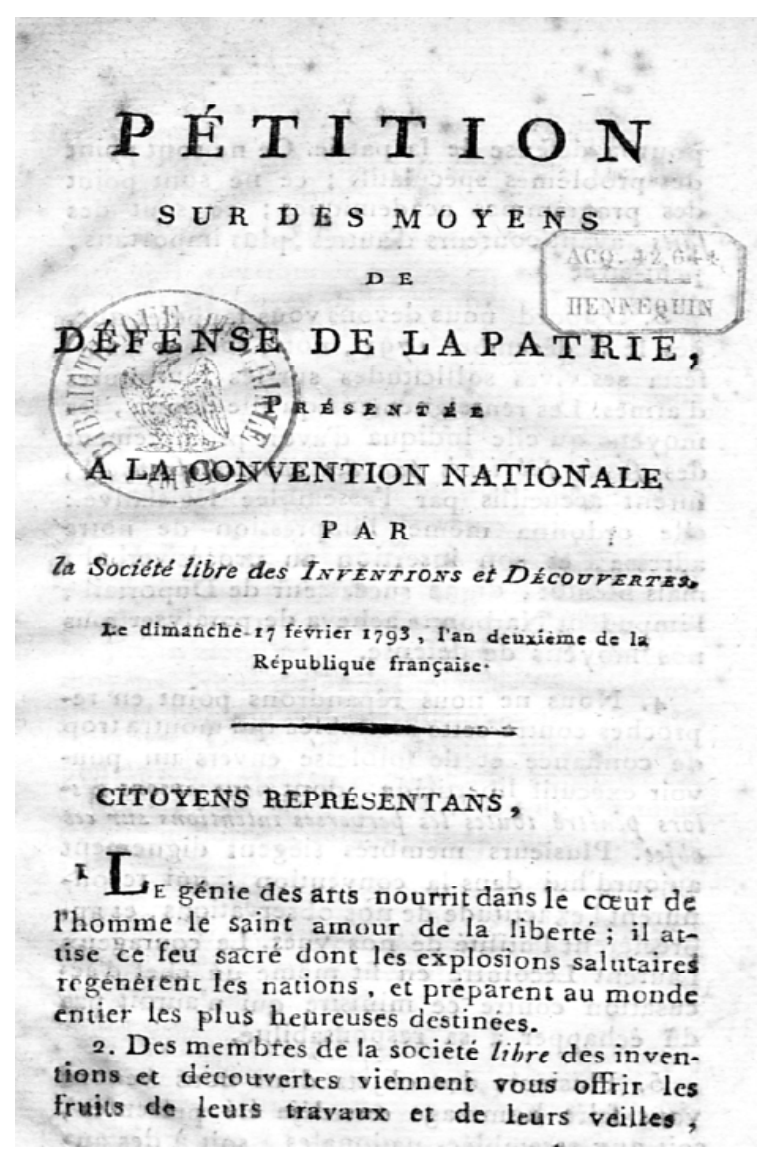

Fig. 1 : Pétition sur des moyens de défense de la Patrie présentée à la Convention nationale par la Société des inventions et découvertes le dimanche 17 février 1793 (an II), Paris, Imprimerie du Cercle social, 4 rue du Théâtre-français, s.d., lère page (BnF, Paris)

en octobre 1793, elle a fait imprimer, sous le bandeau "Liberté Égalité Fraternité », un rapport sur les travaux du métallurgiste Jean-Baptiste Delaplace, membre de la Société, en vue de l'amélioration de la fonte douce pour la fabrication des canons ${ }^{45}$; dans ce texte très détaillé, on apprend qu'une députation de la Société a accompagné Delaplace à la Convention, le 24 décembre 1792, pour y exposer ses procédés et qu'elle-même s'est chargée, en avril 1793, de faire les frais de nouvelles expériences dont elle demande le remboursement. La liste de fin 1793 s'inscrit dans cette ligne.

Sur les cinquante postulants, tous membres de la Société des inventions et découvertes, ce qui d'ailleurs n'est pas explicitement précisé (le document ne porte pas de titre général), on compte dix-huit mécaniciens, sept constructeurs d'instruments, six entrepreneurs ou

45 Rapport fait à la Société des inventions et découvertes sur les travaux du Citoyen Delaplace pour améliorer les fontes, les fers et les aciers, du 3 octobre 1793, s.l.n.d. petits industriels, cinq horlogers, trois chimistes ou pharmaciens, deux architectes.

Servières qui n'est plus président de la Société des inventions et découvertes depuis avril 1792, figure modestement à son rang alphabétique. II fait valoir qu'

« il s'est appliqué à l'étude des langues mortes \& vivantes, de l'histoire \& du droit public ; des mathématiques, de la physique, de l'histoire naturelle, de la minéralogie, de la chymie, arts \& manufactures \& de l'agriculture. Il a publié sur ces divers objets nombre de mémoires répandus dans plusieurs journaux ॥

et postule pour une place « dans une administration, dans les négociations ou pour la technologie raisonnée des arts \& métiers $\%$.

On relève d'autres noms connus : les constructeurs d'instruments François Dellebarre, Nicolas Fortin et Étienne Lenoir, les chimistes Nicolas Leblanc et Michel Dizé (inventeurs du procédé de fabrication de la soude artificielle), les architectes François Cointeraux (inventeur prolifique de procédés de construction assurant la protection des bâtiments contre les incendies) et Jean-Baptiste Rondelet (qui travaille au Panthéon), l'astronome Alexandre Ruelle, I'hydraulicien Jean-Baptiste Hermand de Trouville... Pour les autres, il s'agit d'artisans à la notoriété aujourd'hui moindre, mais estimés en leur temps, comme Jean Simon Bonnemain, inventeur du « régulateur de feu » (thermostat) expérimenté notamment pour l'incubation des œufs ; L'Homond, connu pour son télégraphe électrique, ses aérostats et ses machines textiles; Jean Paulet, manufacturier en étoffes de soie et inventeur d'un métier à gazes, auteur également de l'Art du fabricant d'étoffes de soie pour les Descriptions des arts et métiers ; Claude Rivey, auteur de nombreux métiers à tisser, ou le mécanicien d'origine allemande Jean Tremel, inventeur de plusieurs machines : pompe pneumatique, métier à filer, grue...

Il faut dire que, depuis le vote des lois protectrices de l'invention, qui a été un grand succès pour elle, la Société des inventions et découvertes est en nette perte de vitesse. II lui a fallu particulièrement subir les assauts de la Société du Point central des arts et métiers, menée par Charles-Emmanuel Desaudray ${ }^{46}$. Les

46 Sur Desaudray, Liliane Hilaire-Pérez, « Des entreprises de quincaillerie aux institutions de la technologie : l'itinéraire de Charles-Emmanuel Gaullard-Desaudray (1740-1832) ", dans Jean-François Belhoste, Serge Benoit, Serge Chassagne et Philippe Mioche dir., Autour de l'industrie : histoire et patrimoine. Mélanges offerts à Denis Woronoff, Paris, Comité pour I'histoire économique et financière, 2004, pp. 547-567. 
attaques des inventeurs mécontents se focalisent particulièrement sur la composition du Bureau de consultation des arts et métiers, avec sa forte représentation académique, d'autant que les manœuvres du ministre Roland pour en limiter les attributions, notamment en retardant le déblocage des crédits des récompenses, les inquiètent et les irritent. Desaudray, lui-même représentant du Point central des arts et métiers au Bureau de consultation, publie en mars 1792 un projet de Nouvelle constitution des sciences, arts et métiers destinée à faire pièce aux projets de réorganisation de l'Académie des sciences qu'il juge trop élitistes ; ce texte à la rédaction duquel sont pourtant associés des commissaires de la Société des inventions et découvertes, porte son empreinte. Largement diffusé, il lui assure le leadership des inventeurs, tout comme la création du Lycée des arts à la fin de cette même année $1792^{47}$.

La Société des inventions et découvertes et celle du Point central s'opposent sur bien des sujets, tout comme leurs présidents, Servières et Desaudray, dont les antagonismes et les rivalités sont profonds. Derrière les attaques personnelles et la surenchère à laquelle ils se livrent, se dessinent des enjeux financiers d'importance et finalement de pouvoir ${ }^{48}$. La discorde ruine I'influence de la société qui, dès l'automne 1791, semble perdre l'exclusivité de la défense des intérêts des inventeurs.

Cet effacement est tangible au niveau des adhésions. Si l'année 1791 a été marquée par une première vague massive (23), qui correspond effectivement à la création officielle de la société et au succès du vote de la loi sur la propriété de l'invention (elle compte une soixantaine de membres à la fin de cette année 1791), les années suivantes, 1792 et plus encore 1793-1794, sont des années de désaffection. Treize entrées nouvelles en 1792, quatre en 1793-1794. Les procès-verbaux conservés pour les séances de janvier et février 1792 relèvent la présence respectivement de 30 et de 21 membres $^{49}$. La Société elle-même

47 Hervé Guénot, « Une nouvelle sociabilité savante : le Lycée des arts ", dans Jean-Claude Bonnet dir., La Carmagnole des Muses. L'homme de lettres et l'artiste dans la Révolution, Paris, A. Colin, 1988, pp. 67-78.

48 Sur Servières et particulièrement son conflit avec Desaudray, Christiane Demeulenaere-Douyère, «L'itinéraire d'un aristocrate au service des ' arts utiles ' : Servières, alias Reth (1755-1804) ॥, Documents pour l'histoire des techniques, 15, 2008, pp. 64-76. 49 En février 1792, alors qu'elle doit quitter l'ancienne église du Sépulcre pour le Louvre, la Société du Point central des arts et métiers se prévaut de 300 membres environ (AN Paris, F/17/1097, dossier 3) ; même si ce chiffre est " gonflé ", il donne une idée du rapport des forces. déplore que «l'activité de ses travaux a été trop longtems suspendue par l'inassiduité de beaucoup de ses membres"; pour "les ramener dans son sein », elle décide de faire publier « un tableau général de ses membres avec leurs demeures $"{ }^{50}$. D'où sans doute aussi cette démonstration publique de patriotisme...

Toutefois ces efforts semblent vains. Viennent alors des années plus sombres encore : aucune réception nouvelle pour les ans III et Iv [septembre 1794-septembre 1796]. L'an ıv, particulièrement, est une année difficile pour la Société des inventions et découvertes. L'arrêté du Directoire du 9 prairial an ı [28 mai 1796], supprimant de fait le Bureau de consultation des arts et métiers et transférant ses attributions au nouvel Institut national, ramène les inventeurs à leur situation antérieure et lui porte un rude coup, en l'excluant ipso facto d'une activité qui lui conférait audience et influence parmi les artistes-inventeurs. En dépit du "droit sacré [des citoyens] d'être jugés par leur pair », une nouvelle fois réaffirmé, et malgré ses protestations, il faut en convenir, bien polies, elle ne parvient pas à se maintenir, non plus que les autres représentants des sociétés savantes ${ }^{51}$.

Il faut attendre l'an v [1796-1797] pour assister à une reprise très nette des adhésions : trente réceptions en l'an v, puis six en l'an vı [1797-1798]. En messidor an vı [1798], elle affiche une liste impressionnante de cent quarante-deux membres ${ }^{52}$. Un dynamisme qui ne se confirmera pas et, les années suivantes, elle semble plutôt vivoter avec seulement une réception nouvelle en l'an vII, puis avec une moyenne de moins de quatre par an jusqu'en $1809^{53}$.

\section{Un projet de société industrielle et commerciale (an vi)} En l'an vı [1798], la Société des inventions et découvertes, qui ajoute "perfectionnements » à son titre, compte, si on l'en croit, cent quarante-deux membres. De quoi justifier l'adoption d'un Règlement (fig. 2), publié chez J. F. Sobry, imprimeur à Paris et lui-même membre de la Société ${ }^{4}$. Sans doute a-t-elle déjà eu

50 Arch. Musée des arts et métiers, NS5 [Reth]/1, pièce 4, extrait du procès-verbal de la SID, séance du $1^{\text {er }}$ août 1793.

51 AN Paris, F/17/3594, lettre des membres de la SID au ministre de l'Intérieur, ler fructidor an iv [18 août 1796].

52 Règlement de la Société des inventions, découvertes et perfectionnements séante à Paris au Louvre, Paris, Imprimerie de J. F. Sobry, s.d. [messidor an v//juin-juillet 1798], 31 p.

53 Soit 3 réceptions en l'an VIII, 8 en l'an $\mathrm{x}$, 3 en l'an $x, 3$ en l'an xl, 2 en l'an xII, 6 en l'an xIII, 5 en 1806, 2 en 1807 et 2 en 1809.

54 Je remercie vivement Valérie Nègre qui m'a communiqué ce document inexistant dans les collections de la BnF. Par ailleurs, Maurice Tourneux, dans sa Bibliographie de l'histoire de Paris pendant la Révolution française, Paris, Impri- 


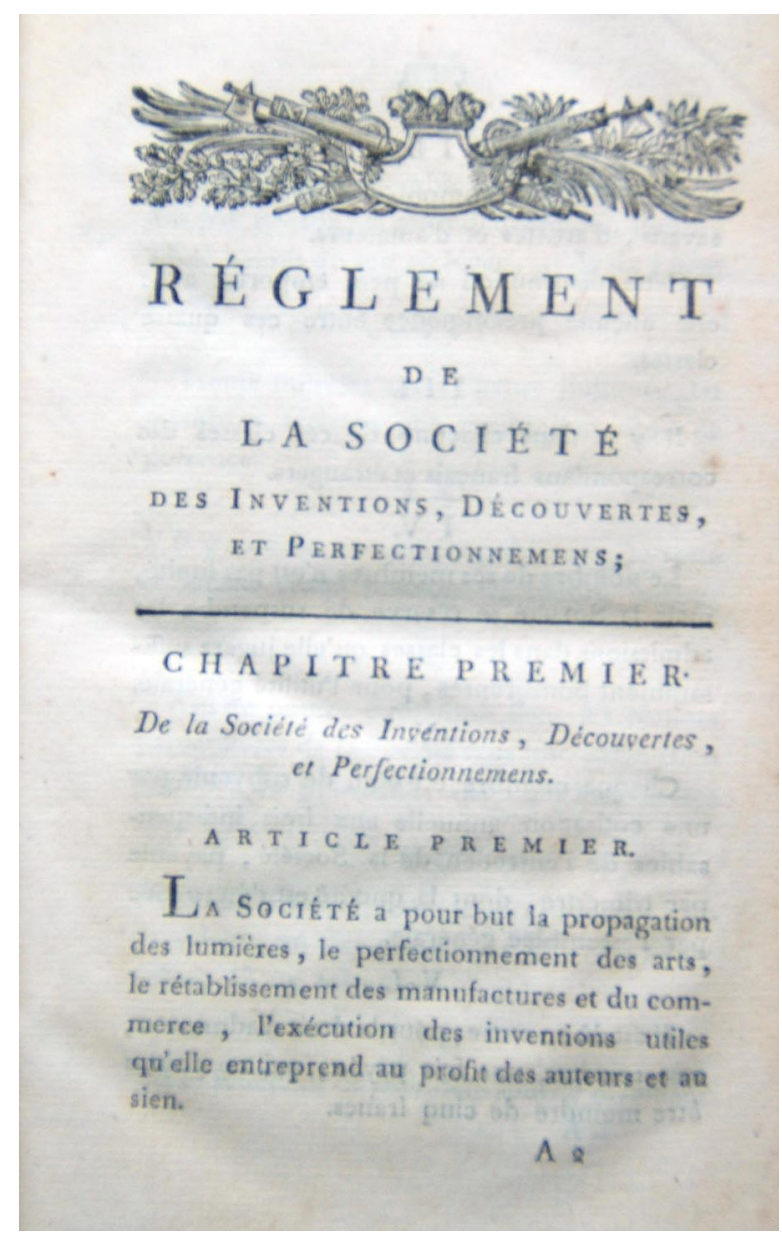

Fig. 2 : Règlement de la Société des inventions, découvertes et perfectionnements séante à Paris au Louvre, Paris, Imprimerie de J. F. Sobry, s.d. [messidor an VI/juin-juillet 1798], 31 p., $1^{\text {ère }}$ p. (Coll. part.).

auparavant un ou plusieurs règlement(s), mais on en ignore tout; on peut penser cependant que celui de l'an vı reprend, au moins en partie, des usages établis antérieurement.

Ce document, qui comprend soixante-cing articles répartis en trois chapitres, indique que l'architecte Jean-Baptiste Rondelet est alors le président de la société et qu'il est assisté de deux secrétaires, le mécanicien Louis Charles Gouault-Monchaux et l'imprimeur Jean-François Sobry.

D'emblée, dans son article premier, le Règlement de l'an vı proclame le but ambitieux que se donne la société : «la propagation des lumières, le perfectionnement des arts, le rétablissement des manufactures

merie nouvelle, 1890-1913, 5 vol., †. 3, n¹7 992, mentionne, sans références, un Projet de nouvelle organisation pour la Société des inventions, découvertes et perfectionnements, Paris, J.-F. Sobry, s.d., 18 p., vraisemblablement antérieur au Règlement... de l'an vl, dont la comparaison avec celui-ci aurait pu être intéressante ; malheureusement, il n'a pas été possible de localiser un exemplaire de ce Projet... et du commerce, l'exécution des inventions utiles qu'elle entreprend au profit des auteurs et au sien ».

Si, pour se démarquer des « arrogances » académiques, la Société des inventions et découvertes fait montre d'une "vertueuse simplicité " 55 , elle se donne néanmoins une organisation très influencée par le modèle académique ${ }^{56}$. "Composée d'inventeurs, de savants, d'artistes et d'amateurs [...] sans prééminence entre ces quatre classes $॥$, la société ne souhaite pas limiter le nombre de ses membres, mais se réserve de suspendre les admissions dans les classes qu'elle jugera suffisamment nombreuses, "pour l'utilité générale ". L'admission se fait moyennant le paiement d'un droit d'entrée, d'au moins cinq francs, et le versement d'une cotisation annuelle, payable par trimestre ${ }^{57}$.

La Société s'assemble deux fois par décade, le primidi et le sextidi, de 5 à 8 heures du soir en hiver, de 6 à 9 en été, soit après la journée de travail ; elle peut aussi tenir des séances publiques ${ }^{58}$.

Le choix des nouveaux membres est strict, les sociétaires se réservant de sélectionner leurs nouveaux associés. II faut faire parrainer sa candidature par deux membres qui certifient les qualités morales du candidat, indiquer ses titres d'admission, subir l'examen d'une commission de quatre membres qui rédigent un rapport, et finalement être élu à la majorité des trois quarts des votants. Il est indispensable d'être domicilié à Paris pour être admis comme sociétaire ; à défaut, on est reçu comme correspondant ${ }^{59}$. Néanmoins, l'admission se concrétise par la remise d'un diplôme (fig. 3).

55 L'expression est de Patrice Bret (L'État, l'armée, la science. L'invention de la recherche publique en France (1763-1830), Rennes, PUR, 2002, p. 71). Selon le Journal des sciences, arts et métiers, la SID « n'a pas la prétention comme ces corporations encore académiques d'avoir le privilège exclusif de penser " (cité par D. de Place, "Le Bureau de consultation pour les Arts, Paris, 1791-1796», op. cit. note 27, p. 141).

56 Sur l'Académie royale des sciences et son règlement de 1699. Christiane Demeulenaere-Douyère et Éric Brian éd., Règlement, usages et science dans la France de l'absolutisme : à l'occasion du troisième centenaire du règlement instituant l'Académie royale des sciences (26 janvier 1699), Paris, Tec \& Doc, 2002.

57 Règlement de la Société des inventions, découvertes et perfectionnements..., op. cit. note 52, art. II à VI.

58 Ibid., art. VII à IX. La SID s'est d'abord réunie dans un local à l'Archevêché, puis à l'hôtel de la Régie (où siégeait le Directoire des inventions), puis au Louvre, dans l'ancienne salle des Pairs, mise à la disposition des sociétés savantes par le gouvernement, à partir d'octobre 1791, et enfin à l'Oratoire ; en l'an VI [1798], elle est à nouveau « séante au Louvre ».

59 Ibid.,art. XXIII à XXXI. 


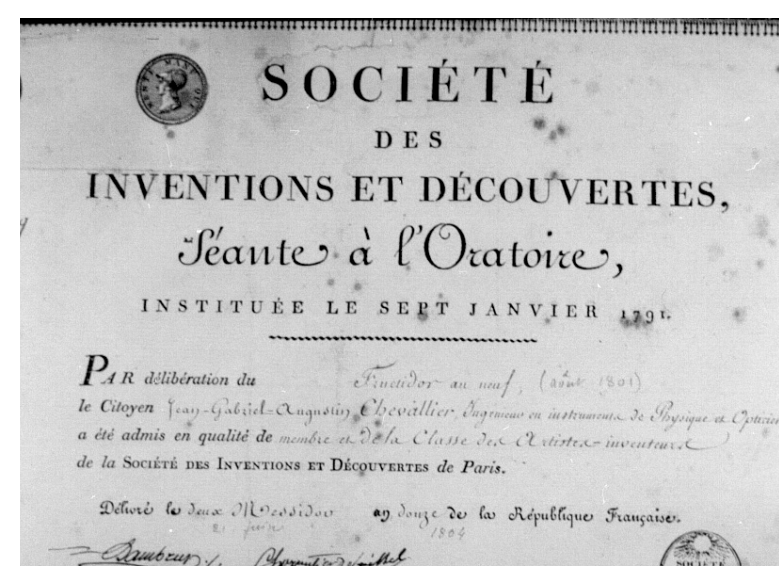

Fig. 3 : Diplôme de la Société des inventions et découvertes, délivré à Jean Gabriel Augustin Chevallier, ingénieur en instruments de physique et opticien, le 2 messidor an XII (Coll. part.).

La société est dirigée par cinq officiers, dont le mandat est de trois mois (sauf pour le trésorier) : un président, qui a pour rôle « de maintenir l'ordre des assemblées, de poser les questions et d'en proclamer les résultats », un vice-président, deux secrétaires qui ont mission de « la confection des procès-verbaux et registres de délibérations, la garde de tous les papiers et autres objets appartenans à la Société ॥, et un trésorier qui « fera toutes les dépenses de la Société sur l'ordre et le visa du président et secrétaire en fonction ; il reçoit en dépôt les fonds de la Société, et tient un compte ouvert à chacun des membres ». Ce dernier, en fonctions pour une année, rend ses comptes tous les six mois à une commission de quatre membres (un par classe), désignée par l'assemblée générale ${ }^{60}$.

Il existe, par ailleurs, trois sortes de commissions, l'une pour l'examen des candidats, deux autres pour l'examen des inventions présentées à la Société et pour leur évaluation; ces deux dernières commissions sont composées de huit membres (deux par classe), à qui il est interdit de faire partie de deux commissions à la fois ${ }^{61}$.

La Société des inventions, découvertes et perfectionnements semble prendre une orientation originale, comme l'annonce la fin de l'article premier : " l'exécution des inventions utiles qu'elle entreprend au profit des auteurs et au sien ». Dans son chapitre II, le Règlement... fait en effet état d'« actions financières » :

"Lorsqu'une invention susceptible de devenir un objet de commerce, est présentée à la société par l'auteur pour en traiter avec elle, il est nommé une commission [...] chargée d'en examiner le mérite

60 Ibid., art. XI à XIX.

$61 \mathrm{lbid}$. , art. XX à XXII.

\begin{abstract}
et les moyens. Si le rapport de cette commission est favorable, il en est nommé une seconde [...] chargée d'évaluer le degré de perfection de l'objet présenté, ce que coûtera sa mise en œuvre, et le bénéfice qu'on aura droit d'en espérer. Sur l'avis des deux commissions réunies, d'examen et d'évaluation, la Société en traite avec l'auteur, et lui propose la portion d'intérêt dans les bénéfices que les deux commissions ont jugé proportionnée au mérite de l'invention et du bénéfice présumable. Le traité est fait [...] ${ }^{62}$.
\end{abstract}

À ce moment de son histoire, elle semble vouloir prendre ses distances avec l'action politique pour se transformer en une société de production qui se chargerait de valoriser certaines inventions "susceptible[s] de devenir un objet de commerce » : en effet, le Règlement parle de « fabrication des objets dont la Société devient propriétaire " et de leur commercialisation, moyennant une participation de la Société aux bénéfices dont une partie serait ensuite redistribuée aux sociétaires sous forme de jetons de présence ${ }^{63}$.

Cette fonction est confiée à une " administration exécutive ", dont le Règlement ne précise pas le mode de recrutement. II énumère plusieurs administrateurs agissant collégialement ; l'un, chef des travaux, choisit les artistes, de préférence membres de la Société, chargés de la fabrication, et passe avec eux des marchés; il surveille, de concert avec l'auteur, le travail de production. L'administrateur chef des magasins tient les stocks d'objets manufacturés. Sont également indiqués un chef de la correspondance, un chef de la comptabilité et un caissier. Cette « administration exécutive ", qui se rémunère sur les bénéfices réalisés, est placée sous le contrôle de deux membres de la Société (choisis dans les commissions d'examen et d'évaluation des inventions) et rend des comptes semestriels, soumis à l'examen et à la vérification d'une commission.

Le financement se fait par le partage des coûts de fabrication entre tous les membres de la société et les administrateurs ; chaque part constitue une "action » cessible. Le produit de la commercialisation, diminué des coûts d'exploitation (matières premières, main d'œuvre et frais d'administration), constitue le bénéfice sur lequel l'" administration exécutive » retient ses honoraires et dont l'inventeur reçoit une part ; «le reste sert à former le dividende et se partage en autant de parts égales qu'il a été formé d'actions ».

62 Ibid., art. XXXII à XXXIV.

$63 \mathrm{lbid}$., art. XXXVI et XXXVII. 


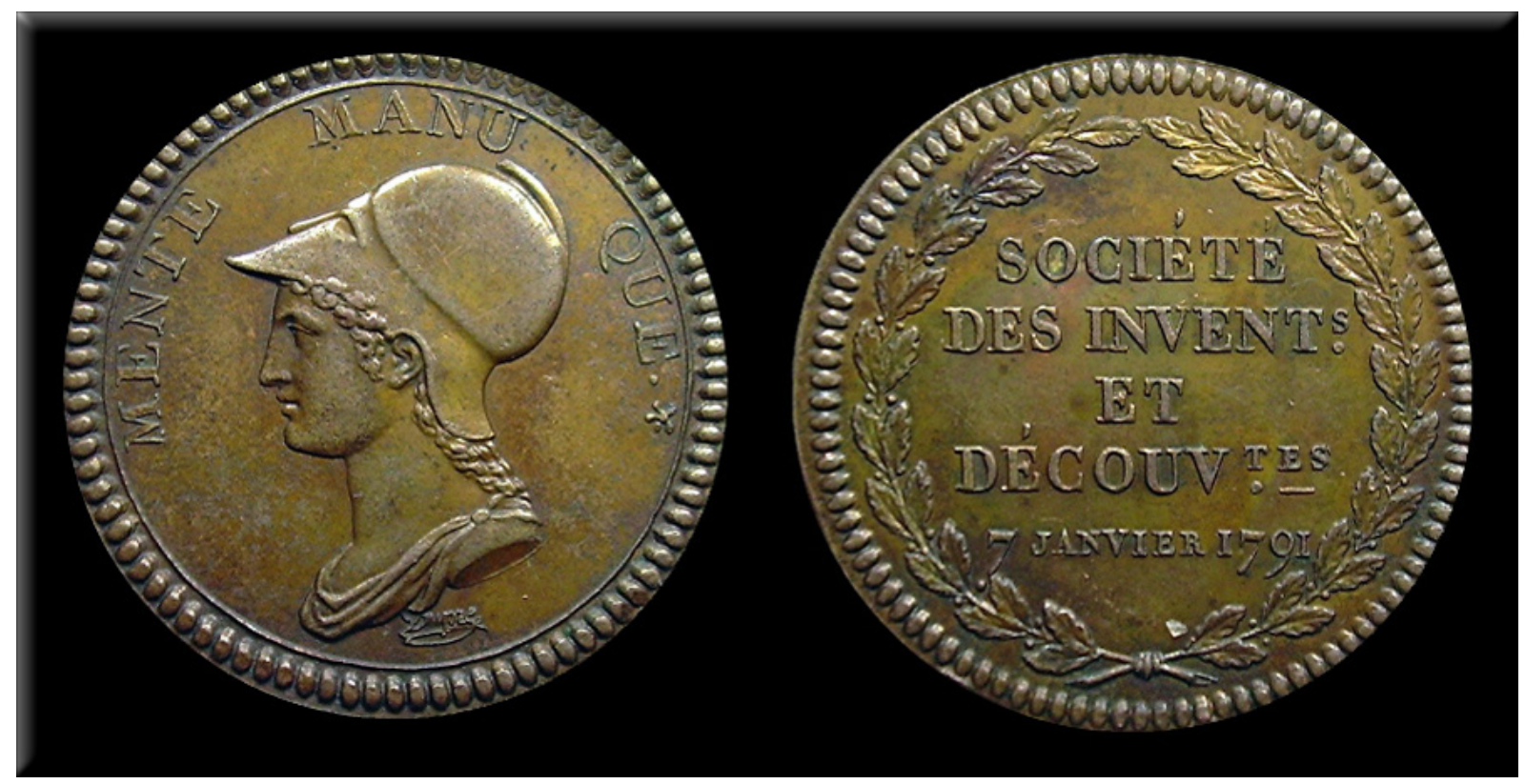

Fig. 4 : Jeton de présence, en bronze, signé par le graveur Dupré : l'avers présente un buste de Minerve casquée de profil vers la gauche entouré de la devise Mente manuque [Par son esprit et par sa main] ; le revers porte, dans une couronne de chêne, l'inscription : Société des invents et découvtes 7 janvier 1791 (http://www.napoleonicmedals.org/coins/h205.htm)

En l'état actuel de nos connaissances, il est difficile d'apprécier jusqu'à quel point ce règlement est entré en exécution ou s'il est resté complètement lettre morte. Néanmoins, il est intéressant en ce qu'il révèle du désir des " artistes-inventeurs ॥ de prendre eux-mêmes en main et collectivement, tout comme ils l'avaient fait sur le plan législatif, en 1791, pour obtenir le vote des lois les protégeant, la fabrication et l'exploitation commerciale du fruit de leur activité créatrice.

\section{Le bilan de 1810-1811}

En 1810-1811, la Société des inventions et découvertes célèbre le vingtième anniversaire de sa création informelle, puis légale. Dans sa séance du 2 novembre 1809, elle décide de publier, à cette occasion,

" sous le nom d'Annuaire, un ouvrage contenant un calendrier, une notice historique sur l'établissement de la société, une liste des inventions qui lui ont été présentées dans le cours de l'année de sa création, une liste des membres actuels et un extrait de ses règlements $1{ }^{64}$.

Cette décision donnera lieu à la parution de deux volumes d'Annuaire en $1810^{65}$. L'heure est venue pour

64 Annuaire [...] pour l'année 1810, op. cit. note 12, p. 48. 65 Annuaire de la Société des inventions et découvertes elle, en effet, de faire retour sur un passé déjà long et d'en dresser le bilan ; elle affirme aussi vouloir établir des relations d'échange avec d'autres sociétés savantes parisiennes ou provinciales. Ainsi, l'Annuaire s'ouvre sur une longue « Notice historique sur la Société des inventions et découvertes ${ }^{66}$, très informative sur les origines de la société et les circonstances qui ont entouré le vote des lois sur l'invention de 1791, et dans laquelle elle revendique pleinement l'action qu'elle a menée auprès de l'Assemblée nationale.

Quant à ses règlements ${ }^{67}$, on peut constater que, s'ils conservent certains points communs avec celui de l'an vı [1798], ils en diffèrent sensiblement sur d'autres.

Les conditions d'entrée dans la société n'ont pas changé. II faut « prouver que l'on est auteur d'une invention ou découverte quelconque ${ }^{68}$. Pratique ancienne, semble-t-il, puisque déjà, le 26 nivôse an ॥ [15 janvier 1794], Auger présentait, " pour titre d'admission », les plans de trois fourneaux et son procédé de « conversion du métal des cloches en bronze ductile ॥ pour fabriquer de l'artillerie et des monnaies ${ }^{69}$. La procédure d'élec-

pour l'année 1810, premier cahier, Paris, Imprimerie de P. N. Rougeron, 1810, 48 p. ; Annuaire de la Société des inventions et découvertes pour l'année 1811, deuxième cahier, Paris, Imprimerie de P. N. Rougeron, 1811,61 p. ; la BnF conserve un exemplaire de ces annuaires ( $\vee 30385$ et $\vee 26567$ ).

66 Annuaire [...] pour l'année 1810, op. cit. note 12, pp. 1-14. 67 Ibid., " Extrait des règlements de la Société ॥, pp. 42-47. 68 Ibid., p. 4 et « Extrait des règlements », art. XVI-XXI.

69 Signalé par Patrice Bret, « Des essais de la monnaie à la recherche et à la certification des métaux : un laboratoire modèle au service de la guerre et de l'industrie (1775-1830) ",, Annales historiques de la Révolution française, $n^{\circ} 320,2000$ (éd. électronique), d'après Arch. Monnaie, fonds Darcet. 
tion reste celle décrite en 1798 ; de même, l'entrée dans la société demeure subordonnée à l'acquittement d'un droit unique d'au moins cinq francs et au versement d'une cotisation annuelle, destinée à subvenir aux frais de l'entretien de la société. Et, comme en 1798, seuls les Parisiens peuvent devenir sociétaires, les autres étant reçus comme correspondants, sans être assujettis à la cotisation annuelle ${ }^{70}$.

Son mode de fonctionnement reste celui de 1798 : quatre "classes » (" Inventeurs », "Savans », "Artistes » et "Amateurs ") comprenant chacune des " correspondants français et étrangers $"{ }^{71}$. Elle se réunit en assemblée générale, le soir, le premier jeudi du mois, et en « commission des travaux » le troisième jeudi ; elle peut aussi tenir des " assemblées publiques". Comme ses membres sont des gens de métier qui vivent des revenus de leur activité, « il est alloué un droit de présence à chaque membre pour chaque assemblée générale et un demi-droit pour la séance de la commission ${ }^{72}$ (fig. 4).

À sa tête cinq officiers : un président, un vice-président, deux secrétaires et un trésorier, dont le mandat est d'une année, éventuellement renouvelable ${ }^{73}$. Mais cette situation semble évolver : en 1811, Jean-Baptiste-Charles Marchais est désigné comme « secrétaire perpétuel $\%$.

En revanche, en 1810, les missions que la société se donne ont évolué sur un point important : « la propagation des lumières, le perfectionnement des arts, et l'examen des inventions utiles aux sciences et au commerce $11^{74}$. Balayé le rêve industrialo-commercial de 1798 ; au nom du principe de réalité, la société a renoncé à ses "actions commerciales», indice sans doute du peu de succès qu'elle a rencontré sur ce point, pour revenir à l'examen et à la publication des machines et procédés nouveaux.

Sur le plan des effectifs, ils ont un peu baissé depuis 1798, mais pas de manière catastrophique. En 1810, elle compte encore cent quinze membres (répartis en vingt-neuf souscripteurs et quatre-vingt-six non souscripteurs) ${ }^{75}$.

Conformément à l'article premier de ses règlements, la Société des inventions et découvertes consacre une part importante de son activité à l'examen

70 « Extrait des règlements », art. V-VI et XXI.

71 Ibid., art. II-IV.

72 Ibid., art. VII-IX. On lui connaît un jeton de présence, en bronze, dû au graveur Dupré, lui-même membre de la SID (voir fig. 4).

73 Ibid., art. XI-XIII.

74 lbid., art. I.

75 Nous ne sommes pas en mesure d'expliquer en quoi ces deux statuts diffèrent. et à l'étude des inventions nouvelles. Les assemblées reçoivent des « artistes ॥ qui viennent y présenter des machines ou des procédés, ou bien entendent le rapport d'un commissaire désigné pour étudier une invention. Elle perpétue ainsi une pratique depuis longtemps en usage, puisque, le 7 germinal an xIII [28 mars 1805], Gouault-Monchaux lit en séance son rapport sur la balance romaine à queue oscillante de Fourché ${ }^{76}$. E† c'est cet aspect particulier de son action qu'elle entend valoriser dans les annuaires de 1810-1811. Elle y publie le bilan de ses travaux, la « liste alphabétique de tous les auteurs qui ont présenté quelques objets d'invention ou d'art " pendant le cours des années 1791 (119 notices), 1792 (52 notices) et 1793 (25 notices) $)^{77}$.

\section{Quelques caractéristiques fortes}

En dépit des lacunes de la documentation, on peut dégager quelques traits originaux qui caractérisent la Société des inventions et découvertes.

D'abord sur le plan du recrutement. Elle recrute majoritairement ses sociétaires parmi les gens de métier ; on s'y retrouve même exclusivement entre praticiens, artisans ou entrepreneurs. L'un des rares à ne pas avoir de liens économiques directs avec le monde de l'industrie est son premier président, le baron de Servières - un authentique aristocrate en rupture avec son milieu d'origine, mais dont, à l'examen, la situation sociale se révèle des plus ambiguës ${ }^{78}$. Par ce recrutement « démocratique», elle se démarque des sociétés techniques qui avaient existé avant elle, comme la Société libre d'émulation de l'abbé Baudeau ; celle-ci, créée en 1776, avait en effet une composition éminemment élitiste (savants, propriétaires, hommes de loi, politiques, familiers des cercles aristocratiques), même si les « artistes » étaient les principaux bénéficiaires de ses subventions ${ }^{79}$.

On y retrouve aussi affirmée, au moins dans les principes, cette «sociabilité transversale » qui était pratiquée dans certaines sociétés techniques antérieures, comme la Société des arts de Paris (1718-1736) ${ }^{80}$, au

76 [Gouault-Monchaux], Rapport fait à la Société des inventions et découvertes, le 7 germinal an xill, sur une romaine à queve oscillante inventée par Fourcher, balancier..., Paris, Pichard, 1805. 77 Dans l'Annuaire... de 1811, on trouve également un rapport sur un chariot présenté par Mathieu en l'an I..

$78 \mathrm{C}$. Demeulenaere-Douyère, op. cit. note 48.

79 Sur la Société d'émulation de l'abbé Baudeau, Liliane Hilaire-Pérez, L'invention technique au siècle des Lumières, Paris, Albin Michel, 2000, pp. 209-220.

80 Liliane Hilaire-Pérez, «L Les sociabilités industrielles en France et en Angleterre au xvII' siècle : réseaux, institutions, enjeux ॥, dans Serge Benoit, Gérard Emptoz et Denis Woronoff éd., Encoura- 


\section{Inventeurs en Révolution}

sein de laquelle se côtoyaient des praticiens de tous ordres, mais qui accueillait également statutairement des savants. Sur ce point cependant, la pratique de la Société des inventions et découvertes contredit ses statuts : bien que son règlement prévoie une classe de "Savants", elle n'en comptera guère parmi ses membres (hormis peut-être les astronomes Ruelle et Vausenville et le mathématicien Legendre).

Cette « sociabilité transversale », elle la réalise plutôt dans un recrutement qui transcende les cadres structurant alors le monde du travail : communautés de métiers ou ateliers. Elle regroupe des artisans appartenant à des professions diverses, ce qui lui permet, en 1791, d'échapper à la loi Le Chapelier interdisant les coalitions entre gens de même métier. Les mécaniciens y sont nettement majoritaires, les constructeurs d'instruments nombreux ; mais on y trouve aussi des horlogers, des opticiens, des serruriers, des arquebusiers, des architectes... À noter aussi un recrutement quasi-exclusivement parisien.

De l'héritage académique, elle garde quelques traits : la répartition de ses membres en « classes ॥, leur distinction entre membres et correspondants, son fonctionnement sous la responsabilité d'officiers, le recours aux commissions d'examen. Mais elle s'en démarque aussi fondamentalement : les inventions qui sont examinées au cours des séances, le sont par des "pairs", d'autres artisans, eux-mêmes pour la plupart inventeurs et qui viendront à leur tour faire examiner leurs propres créations par la Société. Elle obéit ainsi à la revendication des artisans eux-mêmes. Autour de l'examen des inventions et de leur validation, se construit une relation égalitaire et solidaire, où les savoir-faire des uns et des autres se conjuguent et où l'expertise n'est plus enjeu de pouvoir, comme elle l'était à la fin du xvIII siècle, avec le monopole du jugement des experts de l'Académie des sciences ou de l'administration royale. En cela, il y a rupture complète avec les usages contre lesquels les inventeurs se sont insurgés dans les dernières années de l'Ancien Régime.

Mais il reste encore bien des zones d'ombre à explorer. Par exemple, on manque d'éléments d'appréciation sur le statut de ces inventeurs : ouvriers, artisans travaillant seuls ou avec un compagnon, petits entrepreneurs... II ne s'agit pas d'un groupe social homogène et les situations personnelles sont certainement très disparates - ainsi, il y a sans doute un fossé entre certains entrepreneurs comme Bonnot, Desquinemars ou Didier, et Gavoty, mort ruiné en 1810, laissant impayés plusieurs mois de loyer de son galetas et une caisse

ger l'innovation en France et en Europe. Autour du bicentenaire de la Société d'encouragement pour l'industrie nationale, Paris, Éd. du CTHS, 2006, pp. 201-238, ici pp. 206-209. pleine de volumes du Manuel du fileur-cordier dans la publication duquel il a épuisé ses dernières économies. Et il conviendra de poursuivre l'enquête sociale.

De même, sans doute y aurait-il beaucoup d'intérêt à s'interroger sur les rapports de ces inventeurs avec la franc-maçonnerie et à observer de manière plus précise comment ils se positionnent sur l'échiquier politique.

Au final, malgré ses difficultés à fonctionner dans les temps troublés de la Révolution et un certain essoufflement perceptible dans les années 1810-1811, le bilan de l'action de la Société des inventions et découvertes est loin d'être négligeable.

Sur le plan législatif, elle a obtenu de haute lutte le vote des lois fondamentales qui ont réglé le statut de l'invention en France pendant plusieurs décennies, et, sur le plan institutionnel, la création de deux organismes de première importance pour les inventeurs: le Directoire des brevets et le Bureau de consultation des arts et métiers. En opérant, au sein de ce dernier, un partage des pouvoirs, même inégal, avec l'Académie des sciences, elle a enfoncé dans la toute puissance des académiciens un coin que d'autres se sont chargés ensuite de pousser plus loin, jusqu'à détruire l'institution.

Son heure de gloire fut sans conteste l'année 1791 avec le vote des lois sur l'invention, même s'il peut apparaître comme un rendez-vous manqué ou tout au moins inabouti des inventeurs avec la puissance publique. D'autant que cette année fut la seule au cours de laquelle ces questions ont été largement débattues à l'Assemblée nationale ${ }^{81}$. Les assemblées suivantes seront accaparées par d'autres problèmes plus graves et on ne reviendra plus sur ces thèmes avant un demi-siècle. Peut-être, la Société des inventions et découvertes a-t-elle alors pêché par manque d'ambition ou par incapacité à pousser l'avantage plus loin ? Ensuite, sans doute par excès de prudence politique, elle a dû passer la main à d'autres qui se sont faits les porte-parole des inventeurs.

La suite des événements a été moins favorable aux inventeurs dans leur ensemble, puisque le transfert des attributions du Bureau de consultation des arts et métiers à l'Institut national (1796) les a évincés des instances qui décidaient des subventions les concernant. Amère expérience pour la Société des inventions et découvertes, comme pour les autres sociétés d'inventeurs!

81 Dans les tables des Archives parlementaires, l'entrée générale « Inventions et découvertes ॥ n'existe que du vol. 19 au vol. 30, soit d'octobre 1790 à septembre 1791 ; ensuite, les entrées sont au nom des inventions particulières. 
Groupement solidaire constitué autour d'une idée, la Société des inventions et découvertes est difficile à classer. Ni société populaire à caractère politique, ni syndicat inter-professionnel avant l'heure, ni société de secours mutuels, ni coopérative de production ${ }^{82}$, elle se place néanmoins au croisement de chacune de ces dynamiques.

Rassemblés en son sein, les inventeurs y ont fait l'expérience du « collectif » et y ont gagné une identité et une force. Très habilement, ils ont su se constituer en groupe de pression pour obtenir gain de cause auprès de la représentation nationale. Même si l'essai de 1798 semble avoir été moins heureux, ils ont compris aussi l'avantage qu'ils auraient à unir leurs forces, particulièrement financières, pour tirer un parti commercial de leurs créations en se libérant des pourvoyeurs de capitaux.

82 Sur les origines de ces formes d'action collective, André Gueslin, L'invention de l'économie sociale. Idées, pratiques et imaginaires coopératifs et mutualistes dans la France du xIxe siècle, Paris, Économica, 1998, 2éd.
Enfin, par la capacité que ses membres ont eue de prendre confiance en eux-mêmes et de s'organiser, cette société qui recrute largement dans les catégories urbaines populaires, peu éduquées, peu fortunées, ostracisées a priori du processus révolutionnaire ${ }^{83}$, témoigne de l'émergence dans le déba† public des gens de métier par une autre voie que la voie politique bien connue des sociétés populaires, et de leur volonté de prendre en mains collectivement la défense de leurs propres intérêts. Même si cela n'eut qu'un temps...

83 Aucun membre de la SID ne figure parmi les électeurs du Tiers-État nommés par les districts et faubourgs de Paris (Paul Robiquet, Le personnel municipal de Paris pendant la Révolution, Période constitutionnelle, Paris, Jouaust, Noblet et Quantin, 1890, pp. 65-85). Si on trouve parmi eux quelques entrepreneurs comme Trudon ou Réveillon, ou encore le brasseur Santerre ou le tanneur Rubigny de Bertheval, on sait que l'article 13 du Règlement du 13 avril 1789 excluait les artisans des assemblées de district et du droit de vote, attachés aux imposés qui payaient au moins 6 livres de capitation ou justifiaient d'un titre d'office, de grades dans une faculté, d'une commission ou emploi ou de lettres de maîtrise. 


\section{Inventeurs en Révolution}

Annexe 1

État des membres de la Société des inventions et découvertes (SID) fin 1793

(AN Paris, $A B / X I X / 5188$ )

Ce tableau, entré aux Archives nationales (Paris) en 2002, recense les membres de la SID susceptibles d'occuper utilement des emplois publics. Répondant à la circulaire du Comité de Salut public du 23 brumaire an II [13 novembre 1793] qui demandait aux sociétés populaires d'indiquer « la liste des citoyens qui sont les plus propres à remplir les fonctions publiques dans tous les genres ॥, il date très probablement de la fin de l'année 1793. On y compte 50 sociétaires.

Le tableau original étant de grand format et établi en colonnes, il est transcrit ici, pour en faciliter la lecture, sous forme de liste reprenant pour chaque personnage les différentes entrées du tableau.

Nom et prénoms : BILLIAUX Michel

Âge : 42.

Date ef lieu de naissance : Lailly, département de l'Yonne.

Domicile : rue du faubourg Saint-Martin $n^{\circ} 37$, section Bondy.

État : ingénieur en instrumens de physique.

Travaux dans les arts et sciences : Depuis environ 12 années, il s'est occupé de la construction de para-tonnères, tant pour les édifices \& bâtimens que pour les vaisseaux. En 1784, le ministère l'envoya au port de Brest pour cet objet.

Places publiques qu'ils peuvent remplir : le direction d'un attelier d'affûts de canon, de caissons et de tout ce qui y est relatif. Il désire continuer l'état d'ingénieur en instr[uments] de physi[que].

Observations : En ce moment il est occupé à des travaux de ce genre. ll a imaginé une nouvelle voiture pour le transport des malades \& blessés des armées.

Nom et prénoms : BONNEMAIN Jean Simon

Âge : 49.

Date et lieu de naissance : Paris

Domicile : Nanterre près Paris

État : Physicien-méchanicien

Travaux dans les arts et sciences: II a imaginé un régulateur du feu, applicable aux fourneaux \& à tous les appareils du feu, pour établir un degré constant de chaleur. ll a trouvé un moyen de propager un degré égal de chaleur, jusqu'à la distance de 200 pieds, avec la moindre quantité possible de combustible.es publiques qu'ils peuvent remplir : L'inspection des hôpitaux et autres salles d'assemblées pour e renouvellement \& la salubrité de l'air et l'entretien de la chaleur. La direction des serres chaudes dans les établissements nationaux.

Observations : Au commencement de la Révolution, il avoit formé à Nanterre un établissement considérable pour faire éclore artificiellement un grand nombre de poulets. Il a été obligé de suspendre cette utile entreprise, faute de charbon, d'œufs et de grains.

Nom et prénoms : BONNOT Nicolas Claude

Âge : 53.

Date et lieu de naissance : Paris

Domicile : faubourg du Temple $n^{\circ} 23$.

État : entrepreneur de la manufacture de cuivres préparés pour couvrir les bâtimens.

Travaux dans les arts et sciences: Auteur de plusieurs ouvrages sur les bâtimens; entr'autres du détail des fers des bâtimens, in- $8^{\circ}$ de 500 pages.

Places publiques qu'ils peuvent remplir : L'inspection générale des fers, fontes, cuivres \& plombs, tant pour les constructions neuves que pour les réparations des édifices nationnaux.

Observations: II se propose de remettre au Comité de Salut public un mémoire particulier sur des moyens d'économie dans les bâtimens, dont il s'est occupé depuis 30 années. 
Nom et prénoms : CHARPENTIER François Philippe

Âge : 60 .

Date et lieu de naissance : Blois, département de Cher \& Loire.

Domicile : aux Gobelins, section Sans Cutettes Finistère.

État : méchanicien.

Travaux dans les arts et sciences: Il a imaginé la gravure imitant le lavis; un davier, un échaffaud volant \& une pompe pour les incendies. II a fait la monture de la fameuse lentille du jardin de l'Infante.

Places publiques qu'ils peuvent remplir : pour la méchanique appliquée aux arts et à la guerre.

Observations : Il est occupé maintenant par ordre du Comité de Salut public à l'exécution en grand d'une machine de son invention pour achever \& polir les canons des fusils sans le moyen dangereux des meules. Nommé par la Société au jury des Armes.

Nom et prénoms : COINTERAUX François

Âge : 54 .

Date et lieu de naissance : Lyon.

Domicile : faubourg Saint-Honoré $n^{\circ} 108$, section Champs Élysées.

État : architecte.

Travaux dans les arts et sciences: Il tient une école publique \& gratuite d'architecture rurale, sur laquelle il a publié un traité en plusieurs cahiers, avec figures, qui a été distribué aux trois assemblées nationales.

Places publiques qu'ils peuvent remplir : pour l'architecture rurale et l'agriculture. Propre à la régie des Biens nationaux.

Observations: Comme ancien expert \& arpenteur juré, il pourroit être employé dans les bureaux d'une administration publique. II est père de 6 filles.

Nom et prénoms : DELLEBARRE Lovis François

Âge : 67 passés.

Date et lieu de naissance : La Haye en Hollande. Établi à Paris depuis 1776.

Domicile : rue Saint-Germain l'Auxerrois n 47 , section Museum.

État : opticien.

Travaux dans les arts et sciences : Il a été membre de l'académie de Leyde, où il a professé partie des mathématiques \& de la physique, la géographie astronomique, la philosophie, les langues latine \& franç [aise]. Auteur d'un microscope universelle [sic] connu \& recherché dans toute l'Europe.

Places publiques qu'ils peuvent remplir : pour l'optique \& surtout pour les microscopes.

Observations : Il compte mettre au jour plusieurs machines d'optique sur de nouveaux principes. II se propose de publier son ouvrage contenant beaucoup d'observations neuves sur l'histoire naturelle \&a.

Nom et prénoms : DIDIER Henry

Âge : 45 .

Date et lieu de naissance : de la commune du Pys, dép[artemen]t de la Drôme.

Domicile : quai de la féraille $n^{\circ} 64$, section Museum.

État : chapelier, boursier \& ceinturonnier.

Travaux dans les arts et sciences: Auteur d'un vernis souple qui s'applique sur les chapeaux, casques de feutre ou de cuir, toiles \& fournimens des troupes. Il a donné le modèle de casque employé pour l'infanterie. A perfectionné la machine angloise propre à refendre les cuirs.

Places publiques qu'ils peuvent remplir : pour tous les objets relatifs à son art.

Observations : ne peut occuper d'autre place que sa manufacture qui est dans la plus grande activité pour le service des armées. 


\section{Inventeurs en Révolution}

Nom et prénoms : DIZE Michel Jean Jérôme

Âge : 30 .

Date et lieu de naissance : Aire, département des Landes.

Domicile : rue du Sépulcre $n^{\circ} 652$.

État : pharmacien principal du laboratoire général des hôpitaux militaires de la République.

Travaux dans les arts et sciences : Elève de Jean Darcet, sous lequel il a étudié la chymie. Analyse des monnoyes de bronze du haut empire. Travail sur le métal des cloches. Observations sur la teinture de la noix de galle. Manufacture de soude.

Places publiques qu'ils peuvent remplir : pour la chymie pharmaceutique.

Observations : [néant].

Nom et prénoms : DROZ Jean Pierre

Âge : 47.

Date et lieu de naissance : La Chaux de Fonds en Suisse.

Domicile : rue Hautefeuille $n^{\circ} 17$, section Marat.

État : graveur en médailles et méchanicien.

Travaux dans les arts et sciences : Il s'est constamment appliqué à la perfection du monnoyage \& de tout ce qui y a rapport. Les sols anglois \& les pièces de monneron ont été frappés à Birmingham par ses procédés. II a été employé à la fabrication des assignats. C'est lui qui a multiplié les médaillons en taille douce de l'assignat de $25 £$.

Places publiques qu'ils peuvent remplir : propre à perfectionner toutes les parties de l'art monétaire.

Observations: Il consacre le reste de sa vie à faire l'histoire métallique de la Révolution. Actuellement il s'occupe à monter les atteliers et à construire toutes les machines nécessaires pour cet objet.

Nom et prénoms : FEUILLET Gabriel

Âge : 53 .

Date et lieu de naissance: Ardevon, département de la Manche.

Domicile : rue Geoffroy l'Asnier n 22, section Maison-commune.

État : arquebusier depuis 33 ans.

Travaux dans les arts et sciences: Auteur d'une platine de fusil simple et perfectionnée qui lui a mérité la maximun des récompenses nationales et la mention honorable.

Places publiques qu'ils peuvent remplir : propre aux atteliers de construction pour l'arquebuserie.

Observations: Il est l'un des chefs d'attelier, instituteurs d'élèves en arquebuserie à la manufacture d'armes, maison Bretonvilliers, île de la Fraternité, où l'on ne fait que des réparations.

Nom et prénoms : FERON André

Âge : 59 .

Date et lieu de naissance : Brecey, département de la Manche.

Domicile : quay de la Vallée $n^{\circ} 23$, section Marat.

État : horloger méchanicien.

Travaux dans les arts et sciences : quantième perpétuel ; un compensateur; deux échappemens à repos ; quatre à vibrations libres. Quatre outils ou machines pour la perfection de l'horlogerie ; l'un fait \& finit toutes les espèces des roves d'échappement à repos; machine à tailler des limes \& fraises de toutes les formes. Recherches sur les longitudes.

Places publiques qu'ils peuvent remplir : pour les outils \& machines propres à l'exécution de l'horlogerie.

Observations : Il travaille à un fusil d'un nouveau genre. Il a imaginé \& exécuté un affût de canon de 4 livres de balle qui procure un double mouvement horisontal \& vertical à la volonté du pointeur. Désireroit qu'on lui en fît construire deux avec diverses perfections. 


\section{Christiane Demeulenaere-Douyère}

Nom et prénoms : FORTIN Nicolas

Âge : 43 .

Date et lieu de naissance : Mouchy la Ville département de l'Oise.

Domicile : place Beaurepaire, cy devant Sorbonne, section Beaurepaire.

État : ingénieur en instrumens de mathématiques \& de physique.

Travaux dans les arts et sciences : perfection de la machine pneumatique \&a.

Places publiques qu'ils peuvent remplir : propre à tous les objets relatifs à son art.

Observations : Il s'est occupé à la construction des étalons des nouvelles mesures de capacité.

Nom et prénoms : FOURNIER Claude

Âge : 59.

Date et lieu de naissance : Des Granges, dép[artemen]t de l'Aube.

Domicile : aux Quinze vingt, rue Charenton, comme artiste, section des 15/20.

État : méchanicien et fabricant.

Travaux dans les arts et sciences: a simplifié les cardes méchaniques pour la filature du coton.

Places publiques qu'ils peuvent remplir : Ne demande aucune place ; mais il désireroit qu'on lui donnât un adjoint pour terminer son cours d'essais sur la filature \& la fabrication des étoffes de coton.

Observations : Il est infirme par suites d'une paralysie.

Nom et prénoms : FREMINET Claude Nicolas

Âge : 53.

Date et lieu de naissance : le 22 juin 1741, Lagni sur Marne.

Domicile : rue des postes $n^{\circ} 8$.

État : méchanicien de la Marine.

Travaux dans les arts et sciences : auteur $1^{\circ}$ d'une machine à plonger, dont il a été fait les expériences les plus satisfaisantes à Brest \& Rochefort. $2^{\circ}$ d'une méchanique pour la remonte des batteaux. $3^{\circ}$ d'un modèle de voiture sans essieu.

Places publiques qu'ils peuvent remplir : Pour l'emploi de la machine à plonger, sur les côtes \& dans les ports. Observations : [néant].

Nom et prénoms : GALLET François

Âge : 58 .

Date et lieu de naissance : Lizé, département d'Indre \& Loire.

Domicile : rue de Viarme $n^{\circ} 54$, section Halle au bled.

État : sellier méchanicien.

Travaux dans les arts et sciences : Il a imaginé et exécuté une bellandre très commode pour le transport des malades \& blessés.

Places publiques qu'ils peuvent remplir : L'inspection des atteliers pour les charrois \& équipages \& des hopitaux ambulans.

Observations : Il a fait cinq campagnes en Allemagne, en qualité de sellier, à la suite des armées.

Nom et prénoms : GASS Adam Frédéric

Âge : 50 .

Date et lieu de naissance : Shula, petite ville de [gratté : Franconie] Saxe, à Paris depuis 30 ans.

Domicile : rue Saint-Maur n 25 , Basse Courtille, section du Temple.

État : émailleur-chymiste.

Travaux dans les arts et sciences : Il a perfectionné la porcelainne, l'émail \& ses couleurs. II annonce avoir un procédé sûr \& fondé sur la théorie, pour faire d'excellent flint-glass.

Places publiques qu'ils peuvent remplir : propre aux travaux de la verrerie \& des porcelaines. 


\section{Inventeurs en Révolution}

Observations : Il a été employé à la manufacture de Sèv[r]es. Occupé en ce moment par la Commission des poids \& mesures pour traiter le platine en grand. A inventé une cartouche pour accélérer le tir des armes à feu et un pistolet à 7 coups.

Nom et prénoms : GAUTIER

Âge : 64 .

Date et lieu de naissance : Marseille, département des Bouches du Rhône.

Domicile : rue des Vieux Augustins, hôtel de Beauvais, section Guillaume Tell.

État : naturaliste.

Travaux dans les arts et sciences: Pendant 28 années il a voyagé dans l'Amérique méridionnale \& dans l'intérieur des terres de l'île de Cayenne où il a fait les découvertes les plus riches sur les trois règnes. II excelle pour la préparation \& la conservation des animaux.

Places publiques qu'ils peuvent remplir : la direction d'un cabinet national d'histoire naturelle.

Observations: [néant].

Nom et prénoms : GAVOTY Jean François

Âge : 60 .

Date et lieu de naissance : le 13 août 1733, Toulon, dép[artemen] du Var.

Domicile : rue Charonne $n^{\circ} 145$, section Popincourt.

État: [néant].

Travaux dans les arts et sciences : En 1775 il avoit établi à Paris un manufacture de sparterie \& des atteliers pour travailler la filasse de l'agave americana. Plusieurs mémoires sur la culture de ces plantes \& d'autres. A invité [pour inventé ?] une machine hydraulique pneumato-syphon.

Places publiques qu'ils peuvent remplir : pour la sparterie \& tout ce qui y a rapport.

Observations: [néant].

Nom et prénoms : GEORGET Jean André

Âge : 58 .

Date et lieu de naissance : Neuvelire.

Domicile : rue Saint-Denis $n^{\circ} 79$, près la fontaine du Ponceau, section Amis de la patrie.

État : serrurier-méchanicien.

Travaux dans les arts et sciences: auteur de 6 inventions de serrurerie, propres à la sécurité de tous les citoyens.

Places publiques qu'ils peuvent remplir : pour la serrurerie \& les objets relatifs à son art.

Observations : [néant].

Nom et prénoms : GERMAIN Philippe

Âge : 46.

Date et lieu de naissance : Lacenas, département de Rhône \& Loire.

Domicile : Grande fripperie, section Marchés.

État : Fabricant de bas, tricots \& réseaux de dentelle.

Travaux dans les arts et sciences: Plusieurs inventions dans son art.

Places publiques qu'ils peuvent remplir : propre aux atteliers publics relatifs à la fabrication des tricots \&a.

Observations : Il a trouvé les moyens d'occuper aux différentes espèces de métiers à bas \& à tricots les individus qui n'auroient qu'un bras et qu'une jambe. 
Nom et prénoms : GREGOIRE Gaspard

Âge : 42.

Date et lieu de naissance : Aix, département des Bouches du Rhône.

Domicile : rue Grenelle Saint-Honoré $n^{\circ} 33$.

État : méchanicien.

Travaux dans les arts et sciences: Inventeur des tableaux en velours. Auteur d'un mémoire imprimé sur les couleurs des bulles de savons.

Places publiques qu'ils peuvent remplir : propre à la fabrication des étoffes de soye.

Observations : ou à des parties d'administration relatives à la comptabilité.

Nom et prénoms : HERISSON Jean

Âge : 62.

Date et lieu de naissance : le 5 février 1732, Verdun, département de la Meuse.

Domicile : rue des Tournelles au Marais $n^{\circ} 66$, section Indivisibilité.

État : arquebusier.

Travaux dans les arts et sciences: II a fabriqué des armes à feu d'un genre nouveau. II a inventé des ressorts de voiture d'une seule feuille \& très solides. Auteur d'un projet d'usine pour fabriquer du fer blanc à l'instar de celui d'Angleterre.

Places publiques qu'ils peuvent remplir : propre à tout ce qui concerne l'arquebuserie.

Observations: [néant].

Nom et prénoms : D'IVERNOIS Jean Henry

Âge : 62 .

Date et lieu de naissance : Nismes, département du Gard.

Domicile : rue des fossés St Germain des prés $n^{\circ} 21$, section Marat.

État : horloger.

Travaux dans les arts et sciences : Diverses inventions dans son art. [barré en croix au crayon].

Places publiques qu'ils peuvent remplir : propre aux objets relatifs à son art \& à la fabrication des armes [rayé d'un trait au crayon].

Observations : ll est juré d'accusation au tribunal criminel du département de Paris.

Nom et prénoms : JOÜANIN François Motien

Âge : 60 .

Date et lieu de naissance : Paris.

Domicile : au Louvre, section Museum.

État : horloger.

Travaux dans les arts et sciences : Il s'est, depuis 40 ans, occupé de la perfection de l'horlogerie.

Places publiques qu'ils peuvent remplir : Il offre de faire des élèves dans son art.

Observations : [néant].

Nom et prénoms : LACHICHE Claude (Quentin)

Âge : 74 .

Date et lieu de naissance : le 31 8[octo]bre 1719, Dole, département du Jura.

Domicile : rue Montagne Ste Geneviève $n^{\circ} 77$.

État : général de brigade, ancien officier du corps du Génie.

Travaux dans les arts et sciences : mémoire sur la conservation \& la défense des places. Batterie ambulante. Niveau à pendule fixe. Baromètre de nivellement avec un réservoir en spirale. Planchette à table mobile. Auteur du projet de jonction du Rhône au Rhin, dont il s'occupe depuis plus de 50 ans.

Places publiques qu'ils peuvent remplir : La direction de l'ouverture du canal de jonction du Rhône au Rhin. 


\section{Inventeurs en Révolution}

Observations : Vient d'être appellé par le ministre de la Guerre au Comité des fortifications.

Nom et prénoms : LAPLACE Jean Baptiste

Âge : 58.

Date et lieu de naissance : St Pierremont, département des Ardennes.

Domicile : rue faubourg Poissonnière $n^{\circ} 43$, section Poissonnière.

État : métallurgiste.

Travaux dans les arts et sciences : S'est occupé de la perfection des fontes, fers \& aciers.

Places publiques qu'ils peuvent remplir : propre aux travaux relatifs à l'amélioration des fontes, fers \& aciers.

Observations : * [néant].

Nom et prénoms : LAVOIEPIERRE Jean Baptiste Joachim

Âge : 50 .

Date et lieu de naissance : Paris.

Domicile : rue Victoire nationale $n^{\circ} 8$, section Guillaume Tell.

État : [néant].

Travaux dans les arts et sciences : cheminée en ordre d'architecture. Charrette à fonds surbaissé. Moulin à cylindres de bois pour la vendange. Nouvelles roves. Chaudière à circulation spontanée du fluide. Tablettes de bovillon pour les malades aux armées.

Places publiques qu'ils peuvent remplir : propre à inspecter la construction des voitures pour le service des armées.

Observations : Infirme \& ne pouvant se déplacer.

Nom et prénoms : LEBLANC Nicolas

Âge : 51 .

Date et lieu de naissance : Ivoy le pré, département du Cher.

Domicile : Franciade près Paris.

État : chirurgien \& chymiste.

Travaux dans les arts et sciences : Plusieurs découvertes importantes sur la crystallisation. Auteur d'un procédé \& d'une manufacture pour l'extraction en grand de la soude du sel marin.

Places publiques qu'ils peuvent remplir : Propre à la chymie appliquée aux arts.

Observations : Depuis le mois d'août 1792 il est membre du Directoire du département de Paris.

Nom et prénoms : LEGROS Basile

Âge : 49 .

Date et lieu de naissance : département du Jura.

Domicile : rue Thionville $n^{\circ} 47$, section Marat.

État : horloger.

Travaux dans les arts et sciences : Diverses inventions dans son art.

Places publiques qu'ils peuvent remplir : Propre à l'orthopédie méchanique.

Observations : Il a proposé à la Convention le projet d'une école d'orthopédie. Les Comités de la guerre \& d'instruction publique doivent en faire un prompt rapport.

Nom et prénoms : LENOIR Étienne

Âge : 49.

Date et lieu de naissance : Mer, département du Loir \& Cher.

Domicile : rue basse des Ursins $n^{\circ} 1$, section Cité.

État : ingénieur en instrumens de mathématique. 
Travaux dans les arts et sciences : ll a construit \& perfectionné les principaux instrumens d'astronomie, de marine \& du Génie, afin d'enlever aux Anglois cette branche importante de commerce. Il a construit le premier grand phare parabolique de la tour de Cordouan.

Places publiques qu'ils peuvent remplir : Propre à la construction de tous les instrumens d'astronomie terrestre \& nautique. Il désire faire des élèves.

Observations : En réquisition pour six mois pour la construction des étalons de longueur des nouvelles mesures.

Nom et prénoms : LEREBOURS Noël Jean

Âge : 32

Date et lieu de naissance : [néant].

Domicile : quai de l'horloge.

État : opticien.

Travaux dans les arts et sciences: A fait \& continue à faire d'excellentes lunettes de terre \& de mer.

Places publiques qu'ils peuvent remplir : Propre à la fabrication des objectifs achromatiques.

Observations: [néant].

Nom et prénoms : MATHIEU Antoine Joseph

Âge : 42 .

Date et lieu de naissance: Paris.

Domicile : rue Hautefeuille $n^{\circ} 8$, section Marat.

État : méchanicien.

Travaux dans les arts et sciences: Auteur de lits \& fauteuils méchaniques pour les malades.

Places publiques qu'ils peuvent remplir : Propre à fournir les hôpitaux en lits méchaniques.

Observations : [néant].

Nom et prénoms : MERCKLEIN Jean Godefroi

Âge : 60 .

Date et lieu de naissance : Dresde en Saxe, établi en France depuis plus de 30 ans.

Domicile : rue d'Enfer $n^{\circ} 3$, section Cité.

État : méchanicien.

Travaux dans les arts et sciences : En 1758 il a établi et dirigé en Auvergne, pendant trois ans, une manufacture de quincaillerie \& de boutons uniformes. Transmutation du fer en acier. Dossier \& lits méchani[ques]. Fusil d'ordonnance. Menton artificiel pour un matelot. Marque des cuirs. Trappes en fer pour Paris. Cylindre pour timbrer les assignats \& châssis pour leur vérification.

Places publiques qu'ils peuvent remplir : Il est en état de conduire et de diriger toute sorte de travaux en grand dans les arts méchaniques.

Observations : [néant].

Nom et prénoms : MONCHAUX Louis Charles (Govault)

Âge : 33 .

Date et lieu de naissance : Troyes, département de l'Aube.

Domicile : rue St Roch Poissonnière $n^{\circ} 7$.

État : méchanicien.

Travaux dans les arts et sciences: A imaginé \& exécuté en grand un méchanisme contre la rupture des essieux des grosses voitures.

Places publiques qu'ils peuvent remplir : Propre aux charrois des armées.

Observations : Il est inspecteur de la construction à la Régie nationale des charrois des armées. 


\section{Inventeurs en Révolution}

Nom et prénoms : MONET Guillaume

Âge : 41.

Date et lieu de naissance : Lyon.

Domicile : passage des Petits Pères $n^{\circ} 9$, section Guillaume Tell.

État : fabricant de rubans \& gazes.

Travaux dans les arts et sciences : Il a perfectionné le métier à rubans \& la fabrication des fleurs artificielles.

Places publiques qu'ils peuvent remplir : Propre à étendre le commerce national dans son art.

Observations : [néant].

Nom et prénoms : PAULET Jean

Âge : 62.

Date et lieu de naissance : Nismes, dép[artemen]t du Gard.

Domicile : rue Étienne $n^{\circ} 1$, section Museum.

Éłat : dessinateur-méchanicien pour les étoffes de soye.

Travaux dans les arts et sciences: Auteur de plusieurs inventions, qui se trouvent décrites en partie dans son Art du fabricant d'étoffes de soye.

Places publiques qu'ils peuvent remplir : Propre à tout ce qui concerne le tirage, le moulinage des soyes, \& la fabrication des étoffes avec cette substance.

Observations : Il vient d'être nommé professeur de l'art des tissus par la Commission d'instruction publique du département de Paris.

Nom et prénoms : PERRIN Pierre

Âge : 58

Date et lieu de naissance : Quenne, dép[artemen]t de l'Yonne..

Domicile : rue Moufetard $n^{\circ} 37$, section Finistère.

État : fabricant d'effets méłalliques de toiles métalliques.

Travaux dans les arts et sciences: A perfectionné les toiles métalliques, propres à la fabrication du papier velin \& à une infinité d'autres objets.

Places publiques qu'ils peuvent remplir : Ne demande aucune place; mais il offre \& désire faire des élèves dans son art.

Observations : [néant].

Nom et prénoms : PRUDON Joseph

Âge : 61 .

Date et lieu de naissance : Lesme, départem[en]t de la Haute-Saonne.

Domicile : rue Perpignan, section Cité.

État : menuisier méchanicien.

Travaux dans les arts et sciences: Auteur d'un moulin méchanique \& d'une machine à battre le bled, qu'il est chargé d'exécuter en grand.

Places publiques qu'ils peuvent remplir : Propre à inspecter la conduite des bâtimens \& atteliers de la République.

Observations : [néant].

Nom et prénoms : PUTOIS

Âge : [néant].

Date et lieu de naissance : [néant].

Domicile : quai de l'horloge.

État: opticien.

Travaux dans les arts et sciences: Objectifs achromatiques. 
Places publiques qu'ils peuvent remplir : Propre à tout ce qui concerne son art.

Observations : [néant].

Nom et prénoms : RICHER Jean François

Âge : 49.

Date et lieu de naissance : Surenne.

Domicile : rue de la Calendre $n^{\circ} 27$, passage du Marché neuf.

État : ingénieur en instrumens de physique \& de mathématiques.

Travaux dans les arts et sciences: Hygromètre comparable, machine à diviser, machine à graver, micromètre, machine à monnoyer, modèle d'un nouveau moulin à poudre, hache-paille pour les chevaux, \&a.

Places publiques qu'ils peuvent remplir : Propre à tous les objets qui concernent son art.

Observations : [néant].

Nom et prénoms : RIVEY

Âge : 54 .

Date et lieu de naissance : St Genis les Ollières, dép[artemen]t de Rhône \& Loire.

Domicile : rue Richer n 894.

État : méchanicien en tricots.

Travaux dans les arts et sciences: Diverses inventions dans son art.

Places publiques qu'ils peuvent remplir : Propre à la fabrication des tricots.

Observations : [néant].

Nom et prénoms : ROBIN Robert

Âge : 52 .

Date et lieu de naissance : Chauni.

Domicile : Galeries du Louvre nº 8.

État : horloger.

Travaux dans les arts et sciences : Depuis 40 années, il s'est constamment occupé de la perfection de son art \& surtout de la mesure du temps. II y a fait plusieurs utiles inventions. En 1787 il a exécuté pour l'Espagne un méchanisme qui procure aux fares un mouvement uniforme \& continu, quoiqu'il soit conduit par le mouvement à secousse d'une pendule à seconde. Depuis, il a perfectionné le méchanisme et il désireroit en exécuter un modèle pour les ports de la République.

Places publiques qu'ils peuvent remplir : Propre à l'horlogerie astronomique \& nautique.

Observations : [néant].

Nom et prénoms : RONDELET Jean Baptiste

Âge : 50 .

Date et lieu de naissance : Lyon.

Domicile : Panthéon françois.

État : architecte.

Travaux dans les arts et sciences : Cadran géographique, une grue ; nouvelle pompe. Traité théorique \& pratique en mss sur l'art de bâtir.

Places publiques qu'ils peuvent remplir : propre à la haute architecture.

Observations : inspecteur des travaux du Panthéon françois. 


\section{Inventeurs en Révolution}

Nom et prénoms : RUELLE Alexandre

Âge : 38 .

Date et lieu de naissance : Blois, départ[emen]t de Cher \& Loire.

Domicile : à l'observ[atoire] de la République.

État : astronome.

Travaux dans les arts et sciences: Professeur à l'observatoire de la République.

Places publiques qu'ils peuvent remplir : Demande à conserver sa place.

Observations : Eł en cas de suppression à être employé dans les bureaux de la Marine.

Nom et prénoms : SANDOS LEGENDRE Abraham

Âge : 74.

Date et lieu de naissance : Neuchâtel, en Suisse.

Domicile : rue Grands degrés nº 9.

État : horloger-méchanicien.

Travaux dans les arts et sciences: Plusieurs inventions dans son art \& dans les serrures de combinaison.

Places publiques qu'ils peuvent remplir : Pour les serrures de combinaison.

Observations : [néant].

Nom et prénoms : SERVIERES Claude Urbain (Reth)

Âge : 39.

Date et lieu de naissance : le 10 j[anvi]er 1755, Mende, dép[artemen] te la Lozère.

Domicile : rue l'Évêque $n^{\circ} 1$, section Montagne.

État : membre du Bureau de consultation des arts et métiers.

Travaux dans les arts et sciences: II s'est appliqué à l'étude des langues mortes \& vivantes, de l'histoire \& du droit public ; des mathématiques, de la physique, de l'histoire naturelle, de la minéralogie, de la chymie, arts \& manufactures \& de l'agriculture. II a publié sur ces divers objets nombre de mémoires répandus dans plusieurs journaux.

Places publiques qu'ils peuvent remplir : Dans une administration, dans les négociations ou pour la technologie raisonnée des arts \& métiers.

Observations : [néant].

Nom et prénoms : TREMEL Jean

Âge : 66 .

Date et lieu de naissance : le 16 mars 1727, Waldefeu, diocèse de Spire.

Domicile : au Louvre comme artiste depuis plus de 32 ans, section Museum.

État : méchanicien.

Travaux dans les arts et sciences: Machine pneumatique, métier à faite le réseau de dentelle, grue du port St Nicolas; machines pour la filature de la laine, du coton, du chanvre \& du lin.

Places publiques qu'ils peuvent remplir : Propre à la méchanique en général.

Observations : [néant].

Nom et prénoms : TROUVILLE J. B. E. (Hermand)

Âge : 43 .

Date et lieu de naissance : [néant].

Domicile : rue faubourg St Denis $n^{\circ} 66$

Éłat : hydraulicien.

Travaux dans les arts et sciences: Auteur d'une machine qui élève les eaux sans pompes, leviers, rouages ni méchanique. L'assemblée constituante a rendu un décret en faveur de cette découverte. 
Places publiques qu'ils peuvent remplir : Désireroit être employé au dessèchement des mariais et surtout à la réfection de la machine de Marly, par des moyens qui lui sont personnels.

Observations : membre du Bureau de consultation des arts \& métiers.

Nom et prénoms : VERA Charles

Âge : [néant].

Date et lieu de naissance : Violaine, dép[artemen]t de l'Aisne.

Domicile : rue St Sauveur $n^{\circ} 3$.

État : physicien.

Travaux dans les arts et sciences : Inventeur de la pompe à corde ; auteur d'un nouveau feutrage en grand ; et d'une machine à arçonner la laine.

Places publiques qu'ils peuvent remplir : Inspecteur pour les lits et couvertures dans les hôpitaux et dépôts de mendicité.

Observations : Il procureroit une économie de plusieurs millions.

Nom et prénoms : DEBEZIS Jean Michel

Âge : 43.

Date et lieu de naissance : Corbarieux, dép[artemen]t de la Haute Garonne.

Domicile : rue du Bout du monde.

État : plombier-méchanicien.

Travaux dans les arts et sciences: Appareil pour coercer le méphitisme des fosses d'aisance. Artillerie légère à dos de mulet.

Places publiques qu'ils peuvent remplir : Capitaine de génie de la lère classe \& chef de l'artillerie légère, au départ[ement] du Mont-blanc.

Observations: [néant]. 
Annexe 2

Membres de la Société des inventions et découvertes (SID)

de 1791 à 1810'

\begin{tabular}{|c|c|c|}
\hline Nom & entré le & titres et adresses \\
\hline Andrieu $[\mathrm{x}], \mathrm{m}$. n.s. & $\begin{array}{l}21 \text { floréal an } \mathrm{Vl} \\
\text { [10 mai 1798] }\end{array}$ & $\begin{array}{l}1798 \text { : mécanicien, } 424 \text { rue de Varenne, faubourg Saint-Germain. } \\
1810 \text { et } 1811 \text { : mention. }\end{array}$ \\
\hline $\begin{array}{l}\text { Argand[Ami ou Aimé, 1750- } \\
1803 \text { ? ], m.n.s. }\end{array}$ & $\begin{array}{l}26 \text { brumaire an } \mathrm{VI} \\
{[16 \text { novembre 1797] }}\end{array}$ & $\begin{array}{l}1798 \text { : fabricant de lampes à double courant d'air, } 104 \text { rue Mont- } \\
\text { martre. } \\
1810 \text { et } 1811 \text { : mention. }\end{array}$ \\
\hline $\begin{array}{l}\text { Assier-Péricat [Antoine, v. } \\
\text { 1730-ap. 1802] }\end{array}$ & 1798 ou avant? & $\begin{array}{l}1798 \text { : ingénieur en instruments de physique en verre, } 30 \text { rue Geoffroi } \\
\text { l'Anier. }\end{array}$ \\
\hline Auger & 1794 & 1794 : fondeur. \\
\hline Baradelle, m.n.s. & 20 janvier 1791 & $\begin{array}{l}1791 \text { : signataire de l'acte de constitution initial de la SID. } \\
1792 \text { : ingénieur en instruments de mathématiques, quai de l'Horloge } \\
1798 \text { : même état, } 110 \text {, quai de la Tournelle. } \\
1810 \text { et } 1811 \text { : mention }\end{array}$ \\
\hline Bardel, m.n.s. & $\begin{array}{l}\text { 1er messidor an V } \\
\text { [19 juin 1797] }\end{array}$ & $\begin{array}{l}1798 \text { : fabricant de rubans, } 83 \text { rue Mêlée. } \\
1810 \text { et } 1811 \text { : mention. }\end{array}$ \\
\hline Barreau (François), m.s. & 2 juillet 1807 & $\begin{array}{l}1810 \text { et } 1811 \text { : professeur en l'art du tour, } 57 \text { rue Saint-Victor, au col- } \\
\text { lège du Cardinal Lemoine. } \\
\text { Membre de l'Athénée des arts. }\end{array}$ \\
\hline Barthelemy & 1798 ou avant? & $\begin{array}{l}\text { 1791-1792: membre du Point central des arts et métiers (dom. rue } \\
\text { Saint-Antoine, au café de Malte près Saint-Gervais)? } \\
1798 \text { : fabricant de poudre à canon. }\end{array}$ \\
\hline Baud & 1798 ou avant? & 1798 : mécanicien. \\
\hline Bazaine (Pierre), m.s. & $\begin{array}{l}23 \text { vendémiaire an } \mathrm{XI} \\
\text { [15 octobre 1802] }\end{array}$ & $\begin{array}{l}1810 \text { et } 1811 \text { : contrôleur-jaugeur de l'octroi de Paris, } 1 \text { rue de Lodi. } \\
\text { Membre de l'Athénée des arts. }\end{array}$ \\
\hline Bernier, m.n.s. & $\begin{array}{l}11 \text { pluviôse an } \mathrm{V} \\
{[30 \text { janvier 1797] }}\end{array}$ & $\begin{array}{l}1798 \text { : fabricant de rubans de velours, } 43 \text { rue du faubourg Montmartre. } \\
1810 \text { et } 1811: \text { mention. }\end{array}$ \\
\hline $\begin{array}{l}\text { Billiaux (Michel) } \\
{[\text { v. 1751- ?], m.s. }}\end{array}$ & 2 mai 1793 & $\begin{array}{l}1793 \text { : ingénieur en instruments de physique, } 37 \text { rue du faubourg Saint-Martin } \\
1798 \text { : ingénieur pour les pompes et les paratonnerres, même adresse. } \\
1810 \text { et } 1811 \text { : ingénieur-mécanicien, } 70 \text { rue du faubourg Saint-Martin }\end{array}$ \\
\hline $\begin{array}{l}\text { Boicervoise } \\
\text { (Nicolas-Louis), m.s. }\end{array}$ & $\begin{array}{l}4 \text { pluviôse an XIII } \\
\text { [24 janvier 1805] }\end{array}$ & $\begin{array}{l}1810 \text { et } 1811 \text { : potier d'étain, } 246 \text { rue Saint-Honoré, vis-à-vis la rue de } \\
\text { I'Échelle. } \\
\text { Secrétaire de la SID pour } 1810 .\end{array}$ \\
\hline $\begin{array}{l}\text { Bonjour [François Joseph, } \\
\text { 1754-1811], m.n.s. }\end{array}$ & $\begin{array}{l}6 \text { messidor an } V \\
{[24 \text { juin 1797] }}\end{array}$ & $\begin{array}{l}1798: \text { chimiste, } 296 \text { rue de l'Université. } \\
1810 \text { et } 1811 \text { : mention. }\end{array}$ \\
\hline $\begin{array}{l}\text { Bonnemain (Jean Simon) } \\
\text { [v. 1744-ap. } 1816 \text { ? ], m.n.s. }\end{array}$ & 20 janvier 1791 & $\begin{array}{l}1791 \text { : signataire de l'acte de constitution initial de la SID. } \\
1793 \text { : physicien-mécanicien à Nanterre. } \\
1798 \text { : physicien, à Nanterre. } \\
1810 \text { et } 1811 \text { : mention. } \\
\text { Membre de l'Athénée des arts. }\end{array}$ \\
\hline
\end{tabular}

1 Cette liste cumule les données des procès-verbaux de 1792 (BnF, ms. fr. 8045), de la liste de fin 1793 (AN Paris, AB/XIX/5188), de la liste jointe au Règlement... de 1798, et des annuaires de 1810-1811 (BnF) ; on a joint, le cas échéant, pour les membres qui semblent avoir appartenu également à la Société du Point central des arts et métiers, cette information en italiques (Arch. Musée des arts et métiers, 10³92, 10 nov. 1791-9 oct. 1792). Les identifications ont été faites essentiellement à partir de la Nouvelle biographie générale (Firmin-Didot et Hoeffer) et du Dictionnaire de biographie française, et, pour les horlogers, de Tardy, Dictionnaire des horlogers français, op. cit. note 6. 


\begin{tabular}{|c|c|c|}
\hline $\begin{array}{l}\text { Bonnot (Nicolas Claude) } \\
{[\text { v. 1740-?] }}\end{array}$ & 1793 ou avant? & $\begin{array}{l}1793 \text { : entrepreneur de la manufacture de cuivres préparés pour cou- } \\
\text { vrir les bâtiments, } 23 \text { faubourg du Temple. } \\
1798 \text { : fabricant de cuivres étamés }\end{array}$ \\
\hline Boucher, m.n.s. & $\begin{array}{l}15 \text { prairial an IX } \\
{[4 \text { juin } 1801]}\end{array}$ & 1810 : mention. \\
\hline Bouillet [Nicolas, ? -1800] & 1798 ou avant? & 798 : arquebusier, 108 rue [Saint-]Denis, vis-à-vis [Saint-] Sauveur. \\
\hline Boullay & 1798 ou avant? & 1798 : ingénieur du théâtre des Arts, au théâtre de la rue Feydeau. \\
\hline Boze, m.n.s. & 30 janvier 1791 & $\begin{array}{l}1798 \text { : peintre, au pavillon des archives, cour du Palais national des } \\
\text { sciences et des arts. } \\
1810 \text { et } 1811 \text { : mention. }\end{array}$ \\
\hline Bredin & avant 1793 & 1793 : député par la SID auprès du ministère (AN Paris, F/17/1097/2). \\
\hline $\begin{array}{l}\text { Breguet [Abraham Louis, } \\
\text { 1747-1823, ou son fils, Antoine } \\
\text { Louis, 1776-1858 ?], m.n.s. }\end{array}$ & $\begin{array}{l}21 \text { germinal an } \mathrm{V} \\
{[10 \text { avril 1797] }}\end{array}$ & $\begin{array}{l}1798: \text { horloger, quai de l'Horloge. } \\
1810 \text { et } 1811: \text { mention. }\end{array}$ \\
\hline $\begin{array}{l}\text { Broussaie de La Grais ou } \\
\text { Broussais de la Grey, ou } \\
\text { Brossais, m.n.s. }\end{array}$ & 1798 ou avant? & $\begin{array}{l}1798: \text { ingénieur, rue des Grands-Augustins. } \\
1810: \text { mention. } \\
1811: \text { ingénieur. }\end{array}$ \\
\hline Brun, m.n.s. & $\begin{array}{l}11 \text { germinal an } V \\
{[31 \text { mars 1797] }}\end{array}$ & $\begin{array}{l}1798 \text { : mathématicien, } 16 \text { rue du faubourg [Saint-]Honoré. } \\
1810 \text { et } 1811 \text { : mention. }\end{array}$ \\
\hline $\begin{array}{l}\text { Calla [François Étienne, } \\
\text { 1762-1835], m.n.s. }\end{array}$ & $\begin{array}{l}21 \text { ventôse an } V \\
{[11 \text { mars 1797] }}\end{array}$ & $\begin{array}{l}1798 \text { : mécanicien, aux Menus-plaisirs, faubourg Poissonnière. } \\
1810 \text { et } 1811 \text { : mention. }\end{array}$ \\
\hline Carcel, m.n.s. & $\begin{array}{l}6 \text { ventôse an IX } \\
{[25 \text { février } 1801]}\end{array}$ & 1810 et 1811 : mention. \\
\hline Cardon & 1791 & 1791 : signataire de l'acte de constitution initial de la SID. \\
\hline $\begin{array}{l}\text { Chapotay (Jean-Charles- } \\
\text { François), m.s }\end{array}$ & $\begin{array}{l}6 \text { brumaire an VIII } \\
\text { [28 octobre 1799] }\end{array}$ & 1810 et 1811 : employé au Trésor public, 30 rue de Rochechouard. \\
\hline Chaput & 1798 ou avant? & 1798 : mécanicien, 26 rue du Faubourg [Saint-]Denis. \\
\hline $\begin{array}{l}\text { Charpentier (François Philippe) } \\
\text { [1734-1817], m.n.s. }\end{array}$ & janvier 1791 & $\begin{array}{l}1791: \text { signataire de l'acte de constitution initial de la SID. } \\
1792,1793 \text { et } 1798: \text { mécanicien aux Gobelins. } \\
1810: \text { mention } \\
1811: \text { mécanicien aux Gobelins; « doyen de la Société » et membre } \\
\text { honoraire }\end{array}$ \\
\hline $\begin{array}{l}\text { Charpentier de Foisel (Pier- } \\
\text { re-Jean), m.s. }\end{array}$ & $\begin{array}{l}1^{\text {er }} \text { thermidor an } \mathrm{V} \\
\text { [19 juillet 1797] }\end{array}$ & $\begin{array}{l}1798 \text { : météorologiste, } 18 \text { rue des Prêtres [Saint-]Paul. } \\
1810 \text { et } 1811 \text { : ancien lieutenant général des eaux et forêts, } 19 \text { rue } \\
\text { des Prêtres Saint-Paul. } \\
\text { Membre de l'Athénée des arts. }\end{array}$ \\
\hline Charpentier de Saintot & & voir : Saintot-Charpentier \\
\hline $\begin{array}{l}\text { Chevallier (Jean Gabriel } \\
\text { Augustin), m.s. }\end{array}$ & $\begin{array}{l}\text { fructidor an IX } \\
\text { [août-septe mbre } \\
\text { 1801] }\end{array}$ & $\begin{array}{l}1810 \text { et } 1811 \text { : ingénieur-opticien, } 1 \text { quai de l'Horloge. } \\
\text { Membre de l'Athénée des arts. }\end{array}$ \\
\hline Chrétien, m.n.s. 1791 ? & $\begin{array}{l}11 \text { floréal an IX } \\
\text { [1er mai 1801] }\end{array}$ & $\begin{array}{l}1791 \text { : signataire de l'acte de constitution initial de la SID } \\
1798 \text { : graveur, rue [Saint-]Honoré, vis-à-vis l'Oratoire. } \\
1810 \text { et } 1811 \text { : mention. }\end{array}$ \\
\hline $\begin{array}{l}\text { Cointeraux (François) [1740- } \\
\text { 1830], m.n.s. }\end{array}$ & 19 juillet 1792 & $\begin{array}{l}1793 \text { : architecte, } 108 \text { faubourg Saint-Honoré. } \\
1798 \text { : professeur d'architecture rurale, } 932 \text { rue de l'Université, fau- } \\
\text { bourg [Saint-]Germain. } \\
1810 \text { et } 1811 \text { : mention. }\end{array}$ \\
\hline $\begin{array}{l}\text { Costaz l'aîné [Louis, 1767- } \\
\text { 1842], m.n.s. }\end{array}$ & $\begin{array}{l}6 \text { messidor an V } \\
{[24 \text { juin 1797] }}\end{array}$ & $\begin{array}{l}1798: \text { mathématicien à l'École centrale de la Culture. } \\
1810 \text { et } 1811: \text { mention. }\end{array}$ \\
\hline $\begin{array}{l}\text { Coulon de Thévenot [Jean } \\
\text { Félicité, 1754-1813], m.n.s. }\end{array}$ & 17 mars 1791 & $\begin{array}{l}1798 \text { : tachygraphe, rue Feydeau, au magasin de porcelaine. } 1810 \\
\text { et } 1811 \text { : mention. }\end{array}$ \\
\hline Cressot & 1791 & 1791 : signataire de l'acte de constitution initial de la SID. \\
\hline
\end{tabular}




\section{Inventeurs en Révolution}

\begin{tabular}{|c|c|c|}
\hline Dambrun & 1798 ou avant? & 1798 : artiste amateur, 84 rue [Saint-]Honoré, vis-à-vis [Saint-]Roch. \\
\hline $\begin{array}{l}\text { Darcet [Jean Pierre Joseph, } \\
\text { 1777-1844], m.n.s. }\end{array}$ & $\begin{array}{l}7 \text { fructidor an XI } \\
\text { [25 août 1803] }\end{array}$ & 1810 et 1811 : mention. \\
\hline $\begin{array}{l}\text { Debésis, ou Debézis (Jean } \\
\text { Michel) [v. 1750- ?], m.n.s. }\end{array}$ & 12 novembre 1792 & $\begin{array}{l}1793 \text { : plombier-mécanicien, rue du Bout du Monde. } \\
1798 \text { : plombier. } \\
1810 \text { et } 1811 \text { : mention. }\end{array}$ \\
\hline Delaplace (Jean Baptiste) & & voir : Laplace. \\
\hline $\begin{array}{l}\text { Dellebarre (Louis François) } \\
\text { [1726-1805] }\end{array}$ & 1793 ou avant? & $\begin{array}{l}1793 \text { : opticien, } 47 \text { rue Saint-Germain l'Auxerrois. } \\
1798 \text { : opticien, en Hollande. }\end{array}$ \\
\hline $\begin{array}{l}\text { Delucenaye, ou de Luce- } \\
\text { naye, m.n.s. }\end{array}$ & $\begin{array}{l}16 \text { germinal an } V \\
{[5 \text { avril 1797] }}\end{array}$ & $\begin{array}{l}1798 \text { : ingénieur, } 54 \text { rue des Droits de l'Homme. } \\
1810 \text { et } 1811: \text { mention. }\end{array}$ \\
\hline Delunel & & voir : Lunel \\
\hline Denemet & 1791 & 1791 : signataire de l'acte de constitution initial de la SID. \\
\hline Deshaies des Valons, m.n.s. & 22 septembre 1791 & $\begin{array}{l}1791-1792 \text { : membre du Point central des arts et métiers (dom. à Su- } \\
\text { resnes, près du pont de Neuilly). } \\
1798 \text { : mécanicien, à Suresnes. } \\
1810 \text { et } 1811 \text { : mention. }\end{array}$ \\
\hline $\begin{array}{l}\text { Desquinemar[s] (Étienne } \\
\text { Hermant), m.s }\end{array}$ & $\begin{array}{l}\text { 1er prairial an } V \\
\text { [20 mai 1797] }\end{array}$ & $\begin{array}{l}1798 \text { : musicien et mécanicien, } 37 \text { rue [Saint-]Paul. } \\
1810 \text { et } 1811 \text { : mécanicien, } 21 \text { rue Notre-Dame des Champs. } 1810 \text { : } \\
\text { dirige une fabrique de toiles imperméables à cette adresse. }\end{array}$ \\
\hline Detrouville & & Voir : Trouville \\
\hline Deudon & 1792 ou avant? & $\begin{array}{l}1792 \text { : citoyen, } 4 \text { rue du Théâtre Français [siège du Cercle social]. } \\
1798 \text { : artiste musicien, rue de Savoie. }\end{array}$ \\
\hline $\begin{array}{l}\text { Didier (Henry) [v. 1748- ?], } \\
\text { m.n.s. }\end{array}$ & 3 février 1791 & $\begin{array}{l}1793 \text { : chapelier, boursier et ceinturonnier, } 64 \text { quai de la Ferraille. } \\
1798 \text { : fabricant de cuirs refendus, rue Mouffetard. } \\
1810 \text { et } 1811 \text { : mention. } \\
1810 \text { : transfère sa fabrique de cuirs vernis du faubourg Saint-Denis au } \\
26 \text {, rue de Montmorency (dir. son neveu Lauzin). }\end{array}$ \\
\hline $\begin{array}{l}\text { D'Ivernois (Jean Henry) } \\
\text { [v. 1731-?] }\end{array}$ & 1791 & $\begin{array}{l}1791 \text { : signataire de l'acte de constitution initial de la SID. } \\
1793 \text { : horloger, } 21 \text { rue des Fossés Saint-Germain-des-Prés. } \\
1798 \text { : horloger, } 3 \text { rue du Paon. }\end{array}$ \\
\hline $\begin{array}{l}\text { Dizé (Michel Jean Jérôme) } \\
\text { [1764-1852], m.n.s. }\end{array}$ & 5 avril 1792 & $\begin{array}{l}1793 \text { : pharmacien principal au laboratoire général des hôpitaux mi- } \\
\text { litaires, } 652 \text { rue du [Saint-]Sépulcre. } \\
1798 \text { : chimiste, à l'École militaire. } \\
1810 \text { et } 1811 \text { : mention. } \\
\text { Membre du Lycée des arts. }\end{array}$ \\
\hline Doneaud (Pierre) & 1791 & 1791 : signataire de l'acte de constitution initial de la SID. \\
\hline $\begin{array}{l}\text { Doussin-Dubreuil [Jacques- } \\
\text { Louis, v. 1762-1831], m.n.s. }\end{array}$ & $\begin{array}{l}26 \text { messidor an VIII } \\
\text { [15 juillet 1800] }\end{array}$ & $\begin{array}{l}\text { [chirurgien]. } \\
1810 \text { et } 1811: \text { mention. }\end{array}$ \\
\hline Draucy & 1798 ou avant? & 1798 : ingénieur, 2 rue Neuve [Saint-]Denis. \\
\hline $\begin{array}{l}\text { Droz (Jean Pierre) [1746- } \\
\text { 1823], m.n.s. }\end{array}$ & 8 mars 1792 & $\begin{array}{l}1793 \text { : graveur en médailles et mécanicien, } 17 \text { rue Hautefeuille. } \\
1798 \text { : graveur en médailles, même adresse. } \\
1810 \text { : mention. }\end{array}$ \\
\hline Dubos, m.n.s. & 25 avril 1793 & $\begin{array}{l}1798 \text { : mécanicien, } 16 \text { rue Poupée. } \\
1810 \text { et } 1811 \text { : mention. }\end{array}$ \\
\hline Dumas (Henry) & 1798 ou avant? & 1798 : mécanicien, 6 rue du faubourg [Saint-]Honoré. \\
\hline Dumas, m.n.s. & $\begin{array}{l}16 \text { ventôse an } \vee \\
\text { [6 mars 1797] }\end{array}$ & $\begin{array}{l}\text { 1791-1792: membre du Point central des arts et métiers (ingénieur hy- } \\
\text { draulique, } 26 \text { rue des Maures, faubourg Saint-Martin, près l'ancienne } \\
\text { barrière Saint-Laurent) ; représentant du Point central auprès du Bu- } \\
\text { reau de consultation des arts et métiers. } \\
1798 \text { : ingénieur, } 31 \text { rue des Morts. } \\
1810 \text { et } 1811 \text { : mention. }\end{array}$ \\
\hline
\end{tabular}




\begin{tabular}{|c|c|c|}
\hline $\begin{array}{l}\text { Dupeyrat, ou Dupeira } \\
\text { [Jean-Baptiste Barthélemy, } \\
\text { 1759-1834], m.n.s. }\end{array}$ & $\begin{array}{l}16 \text { germinal an } \mathrm{VI} \\
{[5 \text { avril } 1798]}\end{array}$ & $\begin{array}{l}1798: \text { graveur en cachets, } 37 \text { quai Pelletier. } \\
1810 \text { et } 1811: \text { mention. }\end{array}$ \\
\hline Dupont & 1791 & 1791 : signataire de l'acte de constitution initial de la SID. \\
\hline $\begin{array}{l}\text { Dupré [Augustin, 1748-1833], } \\
\text { m.n.s. }\end{array}$ & $\begin{array}{l}\text { 1er pluviôse an V } \\
\text { [20 janvier 1797] }\end{array}$ & $\begin{array}{l}1798 \text { : graveur général des monnaies, à l'hôtel de la Monnaie. } \\
1810 \text { et } 1811 \text { : mention. }\end{array}$ \\
\hline Durivoir, m.n.s. & $\begin{array}{l}9 \text { ventôse an XIII } \\
\text { [28 février 1805] }\end{array}$ & 1810 et 1811 : mention. \\
\hline Enfantin & 1798 ou avant? & 1798 : fabricant d'étoffes de soie à Romans (Drôme). \\
\hline $\begin{array}{l}\text { Favier [Barthélemy, av. an } \\
\text { Xll-ap. 1811], m.n.s. }\end{array}$ & $\begin{array}{l}6 \text { floréal an XII } \\
{[26 \text { avril } 1804]}\end{array}$ & $\begin{array}{l}1810 \text { et } 1811 \text { : mention. } \\
\text { Membre de la Société académique des sciences de Paris (1804). } \\
\text { Ancien inspecteur des poudres et salpêtres. }\end{array}$ \\
\hline Fayel, m.n.s. & $\begin{array}{l}26 \text { nivôse an IX } \\
\text { [16 janvier 1801] }\end{array}$ & 1810 et 1811 : mention. \\
\hline $\begin{array}{l}\text { Féron (André) } \\
\text { [v. 1734-1807] }\end{array}$ & 1793 ou avant? & $\begin{array}{l}1793 \text { : horloger mécanicien, } 23 \text { quai de la Vallée. } \\
1798 \text { : horloger. }\end{array}$ \\
\hline $\begin{array}{l}\text { Fevillet (Gabriel) [v. 1740- ?], } \\
\text { m.n.s. }\end{array}$ & 13 septembre 1791 & $\begin{array}{l}\text { 1791-1792: membre du Point central des arts et métiers (arquebusier, } \\
7 \text { rue Daval, près la porte Saint-Antoine) } \\
1793 \text { et } 1798 \text { : arquebusier, } 22 \text { rue Geoffroy-l'Anier. } \\
1810 \text { et } 1811 \text { : mention. }\end{array}$ \\
\hline $\begin{array}{l}\text { Fortin (Nicolas) [1750-1831], } \\
\text { m.n.s. }\end{array}$ & 17 mars 1791 & $\begin{array}{l}1791 \text { : signataire de l'acte de constitution initial de la SID. } \\
1793 \text { : ingénieur en instruments de mathématiques et de physique, } \\
\text { place Beaurepaire, ci-devant Sorbonne. } \\
1798 \text { : ingénieur en instruments de mathématiques, place Sorbonne. } \\
1810 \text { et } 1811 \text { : mention. }\end{array}$ \\
\hline $\begin{array}{l}\text { Fourché (Charles-Jérôme), } \\
\text { m.s. }\end{array}$ & $\begin{array}{l}16 \text { ventôse an } \vee \\
{[6 \text { mars 1797] }}\end{array}$ & $\begin{array}{l}1810 \text { et } 1811 \text { : balancier-mécanicien, } 51 \text { rue de la Tixéranderie. } \\
\text { Membre de l'Athénée des arts. }\end{array}$ \\
\hline $\begin{array}{l}\text { Fournier (Claude) } \\
\text { [1735-1825 ?] }\end{array}$ & 1793 ou avant? & $\begin{array}{l}1793 \text { : mécanicien et fabricant, aux Quinze-Vingt, rue de Charenton. } \\
1798 \text { : fabricant de tricots, aux Incurables. }\end{array}$ \\
\hline Fourquier & 1798 ou avant? & $\begin{array}{l}1798 \text { : fabricant de peignes pour les tisserands, faubourg [Saint-]Séver } \\
\text { à Roven (Seine-Maritime). }\end{array}$ \\
\hline Framery m.n.s. & $\begin{array}{l}\text { 1er }^{\text {er }} \text { erminal an } V \\
\text { [21 mars 1797] }\end{array}$ & $\begin{array}{l}1798 \text { : amateur et homme de lettres, } 63 \text { rue Vivienne. } \\
1810 \text { : mention. }\end{array}$ \\
\hline $\begin{array}{l}\text { Fréminet (Claude Nicolas) } \\
{[1741-\text { ?] }}\end{array}$ & 1793 ou avant? & 1793 : mécanicien de la Marine, 8 rue des Postes. \\
\hline Fréminville, m.n.s. & $\begin{array}{l}1 \text { er prairial an } V \\
{[20 \text { mai 1797] }}\end{array}$ & $\begin{array}{l}1798 \text { : opticien, } 628 \text { rue du Bac, faubourg [Saint-]Germain. } \\
1810 \text { et } 1811: \text { mention. }\end{array}$ \\
\hline $\begin{array}{l}\text { Gallet (François) } \\
\text { [v. 1735- ?] }\end{array}$ & 1793 ou avant? & $\begin{array}{l}1793 \text { : sellier mécanicien, } 54 \text { rue de Viarmes. } \\
1798 \text { : sellier. }\end{array}$ \\
\hline $\begin{array}{l}\text { Gando [Pierre François, } \\
\text { 1733-1800 ?], m.n.s. }\end{array}$ & 1798 ou avant? & $\begin{array}{l}1798: \text { graveur et fondeur en caractères, } 410 \text { rue des Maçons. } \\
1810 \text { et } 1811: \text { mention. }\end{array}$ \\
\hline Gaspard & 1798 ou avant? & 1798 : mécanicien \\
\hline $\begin{array}{l}\text { Gass ou Gasse (Adam Fré- } \\
\text { déric) [v. 1743- ?], m.n.s. }\end{array}$ & $1^{\text {er }}$ novembre 1792 & $\begin{array}{l}1793 \text { : émailleur chimiste, } 25 \text { rue Saint-Maur, Basse Courtille. } \\
1798 \text { : chimiste, à Chantilly. } \\
1810 \text { et } 1811 \text { : mention. }\end{array}$ \\
\hline $\begin{array}{l}\text { Gautherot [Nicolas, 1753- } \\
\text { 1803] }\end{array}$ & 1798 ou avant? & 1798 : musicien, physicien et mécanicien, 47 quai de l'Horloge. \\
\hline $\begin{array}{l}\text { Gautier } \\
\text { [1730- ?] }\end{array}$ & 1793 ou avant? & $\begin{array}{l}1793 \text { : naturaliste, rue des Vieux-Augustins, hôtel de Beauvais. } \\
1798 \text { : naturaliste, } 82 \text { rue [Saint-]Victor. }\end{array}$ \\
\hline $\begin{array}{l}\text { Gavoty ou Gavoty de Berte } \\
\text { (Jean François) } \\
{[1733-1810]}\end{array}$ & 1793 ou avant? & $\begin{array}{l}1793 \text { : [état néant], } 145 \text { rue de Charonne. } \\
1798 \text { : fabricant de sparterie, même adresse. }\end{array}$ \\
\hline
\end{tabular}




\section{Inventeurs en Révolution}

\begin{tabular}{|c|c|c|}
\hline Gazerant, m.n.s. & $\begin{array}{l}11 \text { germinal an } \vee \\
{[31 \text { mars 1797] }}\end{array}$ & $\begin{array}{l}1798 \text { : fabricant de cristaux, à la verrerie du Gros-Caillou. } \\
1810 \text { et } 1811 \text { : mention. }\end{array}$ \\
\hline Genard & 1791 & 1791 : signataire de l'acte de constitution initial de la SID. \\
\hline $\begin{array}{l}\text { Georget (Jean André) } \\
\text { [v. 1735- ?] }\end{array}$ & 17 mars 1791 & $\begin{array}{l}1791 \text { : signataire de l'acte de constitution initial de la SID. } \\
1793 \text { : serrurier mécanicien, } 79 \text { rue Saint-Denis, près la fontaine du } \\
\text { Ponceau. } \\
1798 \text { : serrurier pour les serrures de sûreté, même adresse. } \\
1810 \text { : ancien serrurier, } 5 \text { rue Saint-Sébastien, au Pont aux Choux. }\end{array}$ \\
\hline Georget fils (Jean-Marie), m.s. & 6 juillet 1809 & 1810 et 1811 : serrurier, 7 rue de Harlay (aux Deux Clefs). \\
\hline $\begin{array}{l}\text { Germain (Philippe) [v. 1747-?], } \\
\text { m.s. }\end{array}$ & 3 février 1791 & $\begin{array}{l}1793 \text { : fabricant de bas, tricots et réseaux de dentelles, Grande Friperie. } \\
1798 \text { : fabricant de bas, } 147 \text { rue des Mauvaises paroles. } \\
1810 \text { et } 1811 \text { : fabricant de tricots, } 3 \text { rue des Mauvaises paroles. }\end{array}$ \\
\hline $\begin{array}{l}\text { Gingembre [sic pour Gen- } \\
\text { gembre Philippe-Joachim, } \\
\text { 1764-1838], m.n.s. }\end{array}$ & $\begin{array}{l}\text { ler pluviôse an V } \\
\text { [20 janvier 1797] }\end{array}$ & $\begin{array}{l}1798: \text { mécanicien, à l'hôtel de la Monnaie. } \\
1810 \text { et } 1811: \text { mention. }\end{array}$ \\
\hline $\begin{array}{l}\text { Gouault-Monchaux ou } \\
\text { Gouault de Monchaux } \\
\text { (Louis Charles) [v. 1760- ?], } \\
\text { m.s. }\end{array}$ & 20 janvier 1791 & $\begin{array}{l}1791 \text { : signataire de l'acte de constitution initial de la SID. } \\
1791-1792 \text { : membre du Point central des arts et métiers (dom. } 7 \text { rue } \\
\text { Saint-Roch Poissonnière). } \\
\text { 1792, } 1793 \text { et } 1798 \text { : mécanicien, } 7 \text { rue Saint-Roch Poissonnière. } \\
1796 \text { et } 1798 \text { : secrétaire de la SID. } \\
1810 \text { et } 1811 \text { : aide-vérificateur des poids et mesures, } 41 \text { rue Croix des } \\
\text { Petits-Champs. }\end{array}$ \\
\hline $\begin{array}{l}\text { Goussier [Louis Jacques, } \\
\text { 1722-1799] }\end{array}$ & 1798 ou avant? & 1798 : dessinateur, 88 rue des Prêtres [Saint-]Séverin \\
\hline Graf, ou Graffe fils, m.n.s. & $\begin{array}{l}6 \text { ventôse an } X \\
{[25 \text { février } 1802]}\end{array}$ & $\begin{array}{l}1792 \text { : propriétaire de la manufacture royale de cires à cacheter de } \\
\text { Sèvres ( ?) ou au dépôt général, } 264 \text { rue Saint-Thomas du Louvre. } \\
1798 \text { : fabricant de cire à cacheter, } 164 \text { rue [Saint-]Thomas du Louvre. } \\
1810 \text { et } 1811 \text { : mention. }\end{array}$ \\
\hline $\begin{array}{l}\text { Grégoire (Gaspard) [1751- } \\
\text { 1846], m.s. }\end{array}$ & 3 février 1791 & $\begin{array}{l}1791 \text { : signataire de l'acte de constitution initial de la SID. } \\
1793 \text { : mécanicien, } 33 \text { rue de Grenelle Saint-Honoré. } \\
1798 \text { : fabricant de portraits en velours, } 12 \text { rue Neuve-des-Petits-Champs. } \\
1810 \text { et } 1811 \text { : inventeur des peintures en velours, hôtel de Mortagne, } \\
47 \text { rue de Charonne, faubourg Saint-Antoine. }\end{array}$ \\
\hline Guillemot (Louis-Onésime), m.s. & 7 août 1806 & 1810 et 1811 : galonnier, 23 rue Thévenot. \\
\hline Guiraut & 1791 & $\begin{array}{l}\text { 1791-1794 ? : représentant de la SID au Bureau de consultation des } \\
\text { arts et métiers (dom. en } 1792: 3 \text { rue Trainée). } \\
1798: \text { négociant. }\end{array}$ \\
\hline Guyot & 1791 & $\begin{array}{l}1791 \text { : signataire de l'acte de constitution initial de la SID. } \\
1791-1792 \text { : membre du Point central des arts et métiers? (maître } \\
\text { maçon, rue Neuve Saint-Étienne, ancien boulevard Poissonnière, ou } \\
\text { architecte, } 8 \text { rue de Ménilmontant). }\end{array}$ \\
\hline Hanin (Guillaume), m.s. & $\begin{array}{l}11 \text { pluviôse an V } \\
\text { [30 janvier 1797] }\end{array}$ & $\begin{array}{l}1810 \text { et } 1811 \text { : mécanicien, } 23 \text { rue Neuve Notre-Dame, en la Cité. } \\
\text { Président de la SID pour } 1810 . \\
\text { Membre de l'Athénée des arts. }\end{array}$ \\
\hline Hannin (Paul), m.n.s. & $\begin{array}{l}10 \text { prairial an XIII } \\
{[30 \text { mai 1805] }}\end{array}$ & $\begin{array}{l}1798 \text { : fabricant de romaines à cadran, au coin de la rue du Marché- } \\
\text { Palu et de la rue Neuve Notre-Dame, en la Cité. } \\
1810 \text { et } 1811 \text { : mention. }\end{array}$ \\
\hline $\begin{array}{l}\text { Hassenfratz [Jean Henri, } \\
\text { 1758-1827], m.n.s. }\end{array}$ & 2 aoûł 1792 & $\begin{array}{l}1798 \text { : inspecteur des mines, à l'École des mines, rue de l'Université, } \\
\text { faubourg [Saint-] Germain. } \\
1810 \text { et } 1811: \text { mention. }\end{array}$ \\
\hline
\end{tabular}




\begin{tabular}{|c|c|c|}
\hline $\begin{array}{l}\text { Hazard l'aîné (Charles-Fran- } \\
\text { çois) [1758-1812], m.s. }\end{array}$ & $\begin{array}{l}8 \text { prairial an } X \\
{[28 \text { mai } 1802]}\end{array}$ & $\begin{array}{l}1810 \text { et } 1811 \text { : peintre-émailleur pour les yeux et figures d'émail, } 2 \text { rue } \\
\text { Sainte-Apolline. } \\
\text { Membre de l'Athénée des arts. }\end{array}$ \\
\hline Henry, m.n.s. & 1798 ou avant? & $\begin{array}{l}1798: \text { arquebusier, } 20 \text { rue des Marmousets. } \\
1810 \text { et } 1811: \text { mécanicien. }\end{array}$ \\
\hline $\begin{array}{l}\text { Hérisson (Jean) [1732- ?], } \\
\text { m.n.s. }\end{array}$ & 10 mars 1791 & $\begin{array}{l}1791 \text { : signataire de l'acte de constitution initial de la SID. } \\
1793 \text { et } 1798 \text { : arquebusier, } 66 \text { rue des Tournelles au Marais. } \\
1810 \text { et } 1811 \text { : mention. }\end{array}$ \\
\hline $\begin{array}{l}\text { Hildebrand (Frédéric) } \\
\text { [?-1792] }\end{array}$ & 1791 & 1791 : signataire de l'acte de constitution initial de la SID. \\
\hline $\begin{array}{l}\text { Houël (Jean-Pierre-Louis } \\
\text { [Laurent, 1735-1813], m.s. }\end{array}$ & 5 novembre 1807 & $\begin{array}{l}1810 \text { : peintre et graveur, } 12 \text { rue Bailleul, hôtel d'Aligre. } \\
\text { Membre de l'Athénée des arts. }\end{array}$ \\
\hline Hullot & 1791 & $\begin{array}{l}1791 \text { : signataire de l'acte de constitution initial de la SID. } \\
1798 \text { : tourneur, } 31 \text { rue des Écouffes, au Marais. }\end{array}$ \\
\hline $\begin{array}{l}\text { Janety, ou Janetty } \\
\text { [Marc Étienne] }\end{array}$ & 1791 & $\begin{array}{l}1791 \text { : signataire de l'acte de constitution initial de la SID. } \\
1798 \text { : orfèvre, } 38 \text { rue du Colombier, faubourg [Saint-]Germain }\end{array}$ \\
\hline Jeuneux & 1791 & 1791 : signataire de l'acte de constitution initial de la SID. \\
\hline Jolivet & 1798 ou avant? & 1798 : artiste, à Lyon. \\
\hline $\begin{array}{l}\text { Jouanin, ou Jouanain (Fran- } \\
\text { çois Motien [ou François } \\
\text { Mathieu, [1733-an VIII]) }\end{array}$ & 1793 ou avant? & $\begin{array}{l}1793 \text { : horloger, au Louvre. } \\
1798 \text { : horloger, cour du Palais national des sciences et des arts. }\end{array}$ \\
\hline Jouvet, m.n.s. & $\begin{array}{l}\text { 1er messidor an } \mathrm{VI} \\
\text { [19 juin 1798] }\end{array}$ & $\begin{array}{l}1798 \text { : fabricant de bijoux en acier, à la Rotonde du Temple. } 1810 \text { et } \\
1811 \text { : mention. }\end{array}$ \\
\hline Jumelin & 1798 ou avant? & 1798 : médecin, 1050 rue [Saint-]Dominique, faubourg [Saint-] Germain. \\
\hline $\begin{array}{l}\text { Lachiche (Claude Quentin) } \\
\text { [1719-1803] }\end{array}$ & 1791 & $\begin{array}{l}1791 \text { : signataire de l'acte de constitution initial de la SID. } \\
1793 \text { : général de brigade, ancien officier du corps du génie, } 77 \text { rue } \\
\text { de la Montagne Sainte-Geneviève. } \\
1798 \text { : général de brigade et ingénieur. }\end{array}$ \\
\hline Lançon, m.n.s. & $\begin{array}{l}19 \text { frimaire an } \mathrm{XI} \\
\text { [10 décembre 1802] }\end{array}$ & 1810 ef 1811 : mention. \\
\hline Lange & 1791 & $\begin{array}{l}1791 \text { : signataire de l'acte de constitution initial de la SID. } \\
1798 \text { : fabricant de lampes à double courant d'air, } 59 \text { rue [Sainte-] } \\
\text { Avoie }\end{array}$ \\
\hline $\begin{array}{l}\text { Laplace, ou Delaplace } \\
\text { (Jean Baptiste) [v. 1735- ?] }\end{array}$ & 26 septembre 1791 & $\begin{array}{l}1791 \text { : signataire de l'acte de constitution initial de la SID. } \\
1791-1792 \text { : membre du Point central des arts et métiers (artiste en } \\
\text { métallurgie, } 50 \text { rue du faubourg Saint-Martin). } \\
1792 \text { : métallurgiste, rue Royale, au coin de la rue Blanche. } \\
1793 \text { : métallurgiste, } 43 \text { rue du faubourg Poissonnière. } \\
1798 \text { : métallurgiste, } 288 \text { rue des Fossés [Saint-]Germain-des-Prés. }\end{array}$ \\
\hline Larcher, m.n.s. & $\begin{array}{l}16 \text { vendémiaire an IX } \\
\text { [8 octobre 1800] }\end{array}$ & 1810 : mention. \\
\hline $\begin{array}{l}\text { Lavoiepierre (Jean Baptiste } \\
\text { Joachim) [v. 1743- ?] }\end{array}$ & 1793 ou avant? & 1793 : [état néant], 8 rue Victoire nationale. \\
\hline $\begin{array}{l}\text { Leblanc (Nicolas) [1753- } \\
\text { 1806] }\end{array}$ & 1791 & $\begin{array}{l}\text { 1791- ? : représentant de la SID au Bureau de consultation des arts et } \\
\text { métiers (dom. en } 1792 \text { : Maisons-sur-Seine près Saint-Denis). } \\
1793 \text { : chirurgien et chimiste, à Franciade [Saint-Denis] près Paris. } \\
1798 \text { : chimiste, } 44 \text { rue des Blancs-Manteaux. }\end{array}$ \\
\hline Leconte & 1791 & $\begin{array}{l}1791: \text { signataire de l'acte de constitution initial de la SID. } \\
1791-1792: \text { membre du Point central des arts et métiers (chirurgien } \\
\text { ou peintre ?). }\end{array}$ \\
\hline
\end{tabular}




\section{Inventeurs en Révolution}

\begin{tabular}{|c|c|c|}
\hline Ledru (Jacques Philippe), m.s. & $\begin{array}{l}4 \text { fructidor an XIII } \\
{[22 \text { août 1805] }}\end{array}$ & $\begin{array}{l}1810 \text { et } 1811 \text { : docteur en médecine, membre du collège électoral } \\
\text { du département de la Seine, } 2 \text { rue Neuve Saint-Paul. } \\
\text { Membre de l'Athénée des arts. }\end{array}$ \\
\hline $\begin{array}{l}\text { Legendre [Adrien Marie, } \\
\text { 1752-1833] }\end{array}$ & 1798 ou avant? & 1798 : mathématicien, 7 rue [Saint-]Zacharie. \\
\hline Legros (Basile) [1745-ap. 1810] & 1793 ou avant? & 1793 : horloger, 47 rue de Thionville \\
\hline Lejeuneux & 1798 ou avant? & 1798 : naturaliste, île [Saint-]Louis. \\
\hline Le Joyand & 1791 & 1791 : signataire de l'acte de constitution initial de la SID. \\
\hline $\begin{array}{l}\text { Lenoir (Étienne) [1744-1832], } \\
\text { m.n.s. }\end{array}$ & 30 janvier 1791 & $\begin{array}{l}1791 \text { : signataire de l'acte de constitution initial de la SID. } \\
1792 \text { : ingénieur en instruments de mathématiques, rue et hôtel des Ursins. } \\
1793 \text { : même état, } 1 \text { rue Basse des Ursins. } \\
1796 \text { : président de la SID. } \\
1798 \text { : ingénieur en instruments d'astronomie et de marine, hôtel d'Eg- } \\
\text { mont, rue de la place Vendôme. } \\
1810 \text { : mention. }\end{array}$ \\
\hline $\begin{array}{l}\text { Lepaute [Pierre Basile, 1749- } \\
\text { 1843], m.n.s. }\end{array}$ & $\begin{array}{l}16 \text { pluviôse an } \vee \\
\text { [4 février 1797] }\end{array}$ & $\begin{array}{l}1798 \text { : horloger, } 14 \text { rue [Saint-]Honoré, près celle de [Saint-]Florentin. } \\
1810 \text { et } 1811 \text { : mention. }\end{array}$ \\
\hline $\begin{array}{l}\text { Lerebours (Noël Jean) } \\
\text { [1762-1840], m.s. }\end{array}$ & 1793 ou avant? & $\begin{array}{l}1793 \text { : opticien, quai de l'Horloge. } \\
1798 \text { : opticien, « À la Belle Vénus ॥, même adresse. } \\
1810 \text { et } 1811 \text { : ingénieur-opticien de S. M. l'Empereur et Roi, } 13 \text { place } \\
\text { du Pont-Neuf. }\end{array}$ \\
\hline Leturc & 1791 & $\begin{array}{l}1791 \text { : signataire de l'acte de constitution initial de la SID. } \\
1798 \text { : mécanicien pour les fabriques. }\end{array}$ \\
\hline Le Vayer & 1791 & $\begin{array}{l}1791 \text { : signataire de l'acte de constitution initial de la SID ; secrétaire } \\
\text { provisoire de la SID. } \\
1791-1792 \text { : membre du Point central des arts et métiers (dom. hôtel } \\
\text { du Chapitre, enclos du Temple). } \\
1792 \text { : professeur d'architecture pratique et vérificateur, au Grand } \\
\text { hôtel du Chapitre, enclos du Temple. }\end{array}$ \\
\hline Lhomond & 1791 & $\begin{array}{l}1791 \text { : signataire de l'acte de constitution initial de la SID. } \\
1798 \text { : ingénieur, mécanicien, rue de Vaugirard. }\end{array}$ \\
\hline Liégeon, m.n.s. & $\begin{array}{l}4 \text { prairial an XII } \\
{[24 \text { mai } 1804]}\end{array}$ & 1810 : mention. \\
\hline Lobreau-Nouvion & 1798 ou avant? & 1798 : ingénieur, rue [Saint-]Dominique, au Gros-Caillou. \\
\hline $\begin{array}{l}\text { Lossen ou Lausen (Clément), } \\
\text { m.s. }\end{array}$ & $\begin{array}{l}16 \text { germinal an XIII } \\
\text { [6 avril 1805] }\end{array}$ & $\begin{array}{l}1798 \text { : serrurier, fabricant de vis à bois, passage de la Boule blanche, } \\
\text { vis-à-vis les Quinze-Vingt, faubourg [Saint-]Antoine. } \\
1810 \text { et } 1811 \text { : serrurier, } 2 \text { rue Moreau, faubourg Saint-Antoine. }\end{array}$ \\
\hline Lucenay & & voir : Delucenay. \\
\hline Lunel, ou Delunel, m.n.s. & $\begin{array}{l}\text { 1er prairial an } \vee \\
\text { [20 mai 1797] }\end{array}$ & 1810 et 1811 : mention. \\
\hline $\begin{array}{l}\text { Luton (Louis, [1757-1852]), } \\
\text { m.s. }\end{array}$ & $\begin{array}{l}26 \text { pluviôse an } X \\
\text { [15 février 1802] }\end{array}$ & $\begin{array}{l}1809 \text { : secrétaire de la SID. } \\
1810 \text { et } 1811 \text { : inventeur d'une dorure solide sur les cristaux, } 14 \text { Marché } \\
\text { Neuf. } \\
\text { Membre de l'Athénée des arts. }\end{array}$ \\
\hline Machaut & 1798 ou avant? & 1798 : teinturier, 294 rue du Cherche-Midi. \\
\hline Malherbe, m.n.s. & $\begin{array}{l}1798 \text { (?) } 11 \text { ventôse an } \\
\text { XIII [2 mars 1805] }\end{array}$ & $\begin{array}{l}1798 \text { : chimiste, } 96 \text { rue du faubourg [Saint-] Martin. } \\
1810 \text { et } 1811 \text { : mention. }\end{array}$ \\
\hline $\begin{array}{l}\text { Mandres ([Claude Simon,] } \\
\text { abbé de) }\end{array}$ & 1791 & $\begin{array}{l}1791 \text { : signataire de l'acte de constitution initial de la SID. } \\
1798 \text { : mécanicien. }\end{array}$ \\
\hline Mané & 1798 ou avant? & 1798 : tabletier, rue des Arcis, près celle de la Lanterne. \\
\hline
\end{tabular}




\begin{tabular}{|c|c|c|}
\hline $\begin{array}{l}\text { Marchais (Jean-Baptiste- } \\
\text { Charles), m.s. }\end{array}$ & $\begin{array}{l}6 \text { brumaire an IX } \\
\text { [28 octobre 1800] }\end{array}$ & $\begin{array}{l}1810 \text { et } 1811 \text { : chimiste, } 404 \text { rue Saint-Honoré. } \\
\text { Membre de l'Athénée des arts. } \\
\text { Secrétaire perpétuel de la SID en } 1811 .\end{array}$ \\
\hline Marion & 1791 & 1791 : signataire de l'acte de constitution initial de la SID. \\
\hline $\begin{array}{l}\text { Mathieu (Antoine Joseph) } \\
\text { [v. 1751- ?], m.s. }\end{array}$ & 22 mars 1792 & $\begin{array}{l}1793 \text { : mécanicien, } 8 \text { rue Hautefeuille. } \\
1798 \text { : dessinateur, même adresse. } \\
1810 \text { ef } 1811 \text { : ingénieur-mécanicien, } 81 \text { rue de la Harpe. }\end{array}$ \\
\hline Mathis, m.n.s. & 16 avril 1792 & $\begin{array}{l}1798 \text { : fabricant de tricots pluchés, rue de Sèvres, près celle de la } \\
\text { Barouillère. } \\
1810 \text { : mention. }\end{array}$ \\
\hline Mégnié & 1791 & 1791 : signataire de l'acte de constitution initial de la SID. \\
\hline Merklein (Auguste), m.s. & 7 août 1806 & $\begin{array}{l}1810 \text { et } 1811 \text { : mécanicien, } 11 \text { rue de l'École de Médecine. } \\
\text { Membre de l'Athénée des arts. }\end{array}$ \\
\hline $\begin{array}{l}\text { Merklein l'aîné (Jean Godefroi) } \\
\text { [v. 1733-ap. 1817] } 1791\end{array}$ & 1791 & $\begin{array}{l}1791 \text { : signataire de l'acte de constitution initial de la SID. } \\
1792 \text { : mécanicien de la Reine, hôtel du Château-Gaillard, rue d'Enfer } \\
\text { en la Cité. } \\
1793 \text { : mécanicien, } 3 \text { rue d'Enfer. } \\
1798 \text { : mécanicien à l'atelier de précision, cour des Invalides, à l'Arsenal. }\end{array}$ \\
\hline $\begin{array}{l}\text { Merklein (Jean Tobie), } \\
\text { m.n.s. }\end{array}$ & $\begin{array}{l}11 \text { pluviôse an } \mathrm{V} \\
{[30 \text { janvier 1797] }}\end{array}$ & $\begin{array}{l}1798 \text { : mécanicien, } 8 \text { rue de la Ville-l'Évêque, faubourg [Saint-]Honoré. } \\
1810: \text { mention. } \\
1811: 11 \text { rue de l'École de médecine, membre honoraire. }\end{array}$ \\
\hline Michel, m.n.s. & 30 janvier 1791 & $\begin{array}{l}1791: \text { signataire de l'acte de constitution. } \\
1791-1792: \text { membre du Point central des arts et métiers (?). } \\
1798: \text { horloger, rue du Louvre, hôtel d'Angiviller. } \\
1810 \text { et } 1811: \text { mention. }\end{array}$ \\
\hline $\begin{array}{l}\text { Mignard (François-Marie, } \\
[1779-1857]), \text { m.s. }\end{array}$ & 2 janvier 1806 & $\begin{array}{l}1810 \text { et } 1811 \text { : fabricant d'acier à pignon, à la barrière de la Chopi- } \\
\text { nette, à Belleville. }\end{array}$ \\
\hline Migneron, m.n.s. & $\begin{array}{l}26 \text { vendémiaire an II } \\
\text { [17 octobre 1793] }\end{array}$ & $\begin{array}{l}1798 \text { : ingénieur, } 25 \text { rue d'Enfer. } \\
1810 \text { et } 1811: \text { mention. }\end{array}$ \\
\hline $\begin{array}{l}\text { Molard [Claude Pierre, } 1758- \\
\text { 1837], m.n.s. }\end{array}$ & $\begin{array}{l}2 \text { pluviôse an } V \\
\text { [21 janvier 1797] }\end{array}$ & $\begin{array}{l}1798: \text { mécanicien, } 296 \text { rue de l'Université. } \\
1810 \text { et } 1811: \text { mention. }\end{array}$ \\
\hline $\begin{array}{l}\text { Monet, ou Monnet (Guillaume) } \\
\text { [v. 1752- ?] }\end{array}$ & 1793 ou avant? & $\begin{array}{l}1793 \text { : fabricant de rubans et gazes, } 9 \text { passage des Petits-Pères. } 1798 \text { : } \\
\text { négociant, } 35 \text { rue Neuve des Petits-Champs. }\end{array}$ \\
\hline $\begin{array}{l}\text { Montgolfier [Joseph Michel, } \\
\text { 1740-1810], m.n.s. }\end{array}$ & $\begin{array}{l}6 \text { prairial an VII } \\
{[25 \text { mai 1799] }}\end{array}$ & $\begin{array}{l}1798 \text { : physicien, } 104 \text { rue Montmartre. } \\
1810: \text { mention. }\end{array}$ \\
\hline Mossi & 1791 & 1791 : signataire de l'acte de constitution initial de la SID. \\
\hline Muratz, m.n.s. & 6 mai 1791 & $\begin{array}{l}1798 \text { : mécanicien, } 9 \text { rue Contrescarpe, faubourg [Saint-]Marceau. } \\
1810 \text { et } 1811: \text { mention. }\end{array}$ \\
\hline Odelin & $\begin{array}{l}26 \text { prairial an } \mathrm{V} \\
\text { [14 juin 1797] }\end{array}$ & $\begin{array}{l}1791-1792: \text { membre du Point central des arts et métiers (ingénieur, } \\
6 \text { rue du Fouard). } \\
1798: \text { ingénieur des mines, } 692 \text { rue de Babylone. } \\
1810 \text { et } 1811: \text { mention. }\end{array}$ \\
\hline Oudet, m.n.s. & 31 mai 1792 & $\begin{array}{l}1798 \text { : herniaire, } 288 \text { rue des Fossés [Saint-] Germain-des-Prés. } \\
1810 \text { et } 1811: \text { mention. }\end{array}$ \\
\hline Pajot de Charmes, m.n.s. & $\begin{array}{l}6 \text { pluviôse an } V \\
\text { [25 janvier 1797] }\end{array}$ & $\begin{array}{l}1798: \text { directeur de la glacerie de Tourlaville, près Cherbourg. } \\
1810 \text { et } 1811: \text { mention }\end{array}$ \\
\hline Paulet (Jean) [v. 1731- ?] & 1793 ou avant? & 1793 : dessinateur-mécanicien pour les étoffes de soie, 1 rue [Saint-]Étienne. \\
\hline $\begin{array}{l}\text { Perrin (Pierre) [v. 1735- ?], } \\
\text { m.n.s. }\end{array}$ & 1793 ou avant? & $\begin{array}{l}\text { 1791-1792: membre du Point central des arts et métiers (dom. rue } \\
\text { Mouffetard, au Grand Louis, près les Gobelins). } \\
1793 \text { et } 1798: \text { fabricant de toiles métalliques, } 137 \text { rue Mouffetard. } \\
1810: \text { mention. } \\
1811: \text { « auteur des toiles métalliques ». }\end{array}$ \\
\hline
\end{tabular}




\section{Inventeurs en Révolution}

\begin{tabular}{|c|c|c|}
\hline Piron, m.n.s. & $\begin{array}{l}21 \text { ventôse an } V \\
{[11 \text { mars 1797] }}\end{array}$ & $\begin{array}{l}1798: \text { architecte, } 164 \text { rue [Saint-]Marc. } \\
1810 \text { et } 1811: \text { mention. }\end{array}$ \\
\hline $\begin{array}{l}\text { Prudon (Joseph) [v. 1732- ?], } \\
\text { m.n.s. }\end{array}$ & 23 décembre 1792 & $\begin{array}{l}1793 \text { : menuisier mécanicien, rue Perpignan. } \\
1798 \text { : menuisier, } 9 \text { rue [Saint-] Christophe, en la Cité. } \\
1810 \text { et } 1811 \text { : mention. }\end{array}$ \\
\hline Putois, m.n.s. & 3 février 1791 & $\begin{array}{l}1791 \text { : signataire de l'acte de constitution initial de la SID. } \\
1793 \text { et } 1798 \text { : opticien, quai de l'Horloge. } \\
1810 \text { et } 1811 \text { : mention. }\end{array}$ \\
\hline Raimbault & 1791 & 1791 : signataire de l'acte de constitution initial de la SID. \\
\hline Raoul, m.n.s. & $\begin{array}{l}11 \text { pluviôse an } V \\
\text { [30 janvier 1797] }\end{array}$ & $\begin{array}{l}1798 \text { : fabricant de limes, } 28 \text { place de Thionville. } \\
1810 \text { et } 1811 \text { : mention. }\end{array}$ \\
\hline Reignier (Edme), m.s. & $\begin{array}{l}16 \text { prairial an } \vee \\
\text { [4 juin 1797] }\end{array}$ & $\begin{array}{l}1798 \text { : mécanicien, aux Jacobins, rue [Saint-]Dominique, faubourg } \\
\text { [Saint-]Germain. } \\
1810 \text { et } 1811 \text { : conservateur du dépôt central de l'artillerie, } 13 \text { rue de } \\
\text { I'Université. } \\
\text { Membre de l'Athénée des arts. }\end{array}$ \\
\hline $\begin{array}{l}\text { Richer, ou Riché (Jean Fran- } \\
\text { çois) [v. 1744- ?] }\end{array}$ & 1791 & $\begin{array}{l}1791 \text { : signataire de l'acte de constitution initial de la SID. } \\
1791-1792 \text { : membre du Point central des arts et métiers (dom. } 27 \text { rue } \\
\text { de la Calande, passage du Boicelier de Marché Neuf). } \\
1793 \text { : ingénieur en instruments de physique et mathématiques, } 27 \text { rue } \\
\text { de la Calande, passage du Marché neuf. } \\
1798 \text { : ingénieur en instruments de physique, même adresse. } \\
1810 \text { : ingénieur. }\end{array}$ \\
\hline $\begin{array}{l}\text { Rivey, ou Rivet [Claude, } \\
\text { 1740-1831], m.n.s. }\end{array}$ & 26 juillet 1791 & $\begin{array}{l}1791-1792 \text { : membre du Point central des arts et métiers (mécanicien, } \\
894 \text { rue Richer, faubourg Montmartre). } \\
1793 \text { : mécanicien en tricots, } 894 \text { rue Richer. } \\
1798 \text { : fabricant d'étoffes, même adresse. } \\
1810 \text { et } 1811 \text { : mention. }\end{array}$ \\
\hline Robillard & 1791 & $\begin{array}{l}1791 \text { : signataire de l'acte de constitution initial de la SID. } \\
1798 \text { : menuisier, } 15 \text { rue de Montrevil. }\end{array}$ \\
\hline Robin (Robert) [1742-an VII] & 1792 ou avant? & $\begin{array}{l}1792 \text { : horloger du Roi, } 8 \text { galeries du Louvre } \\
1793 \text { et } 1798 \text { : horloger, même adresse. }\end{array}$ \\
\hline $\begin{array}{l}\text { Rondelet (Jean Baptiste) } \\
\text { [1743-1829], m.n.s. }\end{array}$ & 22 septembre 1791 & $\begin{array}{l}1793 \text { : architecte, Panthéon français. } \\
1798 \text { : architecte, } 991 \text { enclos du Panthéon. } \\
1810 \text { et } 1811 \text { : mention. } \\
\text { Président de la SID pour } 1798\end{array}$ \\
\hline Rosa, m.n.s. & $\begin{array}{l}21 \text { germinal an } \vee \\
{[10 \text { avril 1797] }}\end{array}$ & $\begin{array}{l}1798: \text { mécanicien, } 54 \text { rue des Droits de l'Homme. } \\
1810 \text { et } 1811 \text { : mention. }\end{array}$ \\
\hline Roulland, m.n.s. & 5 mars 1792 & $\begin{array}{l}1798 \text { : professeur de physique. } \\
1810 \text { et } 1811: \text { mention. }\end{array}$ \\
\hline $\begin{array}{l}\text { Ruelle (Alexandre) [v. 1756- } \\
\text { ?], m.n.s. }\end{array}$ & 30 janvier 1791 & $\begin{array}{l}1793 \text { : astronome à l'Observatoire. } \\
1798 \text { : astronome, } 567 \text { rue du Bac. } \\
1810 \text { et } 1811 \text { : mention. }\end{array}$ \\
\hline Russenger, m.n.s. & 1810 ou avant? & 1810 et 1811 : fabricant de creusets. \\
\hline $\begin{array}{l}\text { Saintot-Charpentier (Pros- } \\
\text { per-Marie-Michel de), m.s. }\end{array}$ & $\begin{array}{l}6 \text { ventôse an } X \\
\text { [25 février 1802] }\end{array}$ & $\begin{array}{l}1810 \text { et } 1811 \text { : membre du collège électoral du département de la } \\
\text { Seine, } 19 \text { rue des Prêtres-Saint-Paul. } \\
\text { Membre de l'Athénée des arts. }\end{array}$ \\
\hline Salivet & 1798 ou avant? & 1798 : mécanicien, 527 rue [Saint-]Hyacinthe \\
\hline Salneuve, m.n.s. & $\begin{array}{l}\text { ler pluviôse an V } \\
\text { [20 janvier 1797] }\end{array}$ & $\begin{array}{l}1798 \text { : mécanicien, } 26 \text { rue du faubourg [Saint-]Denis. } \\
1810 \text { : mention }\end{array}$ \\
\hline $\begin{array}{l}\text { Sandos-Legendre (Abra- } \\
\text { ham) [v. 1719-?] }\end{array}$ & 1793 ou avant? & 1793 et 1798 : horloger-mécanicien, 9 rue des Grands Degrés. \\
\hline
\end{tabular}




\begin{tabular}{|c|c|c|}
\hline Schimtz, m.n.s. & $\begin{array}{l}\text { frimaire an II } \\
\text { [novembre-décembre } \\
\text { 1793] }\end{array}$ & $\begin{array}{l}1798 \text { : facteur de piano-forte, au Musée, } 1834 \text { rue de Thionville. } \\
1810 \text { et } 1811 \text { : mention. }\end{array}$ \\
\hline $\begin{array}{l}\text { Servières (Claude Urbain } \\
\text { de Retz de), dit Reth [1755- } \\
1804]\end{array}$ & 1791 & $\begin{array}{l}1791 \text { : signataire de l'acte de constitution initial de la SID. } \\
1791-1796 \text { : représentant de la SID au Bureau de consultation des } \\
\text { arts et métiers. } \\
1793 \text { : membre du Bureau de consultation des arts et métiers, } 1 \text { rue } \\
\text { l'Évêque. } \\
1798 \text { : mathématicien et chimiste, } 62 \text { rue d'Argenteuil. } \\
\text { Président de la SID de janvier } 1791 \text { à avril } 1792 \text {. }\end{array}$ \\
\hline Smithz & 1791 & 1791 : signataire de l'acte de constitution initial de la SID. \\
\hline $\begin{array}{l}\text { Sobry (Jean François) [1743- } \\
\text { 1820] }\end{array}$ & $\begin{array}{l}26 \text { floréal an } V \\
\text { [15 mai 1797] }\end{array}$ & $\begin{array}{l}1798 \text { : littérateur et imprimeur, } 149 \text { rue du Bac. Secrétaire de la SID } \\
\text { pour } 1798 . \\
1810 \text { et } 1811 \text { : mention. }\end{array}$ \\
\hline Sutières [Sarcey] (de) & 1791 & 1791 : signataire de l'acte de constitution initial de la SID. \\
\hline Talon, m.n.s. & 2 juillet 1806 & 1810 ef 1811 : mention. \\
\hline Teillard & 1798 ou avant? & 1798 : mécanicien. \\
\hline Teste (Antoine) & 1791 & $\begin{array}{l}1791 \text { : signataire de l'acte de constitution initial de la SID. } \\
1798 \text { : fabricant de rubans, quai Clair à Lyon. }\end{array}$ \\
\hline Tillaie & 1798 ou avant? & 1798 : pompier. \\
\hline Torin, ou Thorin & 1798 ou avant? & $\begin{array}{l}\text { 1791-1792: membre du Point central des arts et métiers (chimiste). } \\
1798 \text { : fabricant de charbon de tourbe, } 779 \text { rue [Saint-]Philippe du } \\
\text { Roule. }\end{array}$ \\
\hline Touroude, m.n.s. & $\begin{array}{l}6 \text { nivôse an VI } \\
\text { [26 décembre 1797] }\end{array}$ & $\begin{array}{l}\text { 1791-1792: membre du Point central des arts et métiers. } \\
1798 \text { : inspecteur des eaux de Paris, à la Ville-l'Évêque, rue de la } \\
\text { Madeleine, faubourg [Saint-]Honoré. } \\
1810 \text { et } 1811 \text { : mention. }\end{array}$ \\
\hline $\begin{array}{l}\text { Touverez [Thouvenez Louis, } \\
\text { av. 1787-?] }\end{array}$ & 1798 ou avant? & $\begin{array}{l}1798 \text { : horloger et mécanicien pour les membres postiches, } 1436 \text { rue } \\
\text { [Saint-]Honoré. }\end{array}$ \\
\hline $\begin{array}{l}\text { Tremel (Jean) } \\
\text { [1727-ap. an VII] }\end{array}$ & 1793 ou avant? & $\begin{array}{l}1793 \text { : mécanicien, au Louvre. } \\
1798 \text { : mécanicien, cour du Palais national des sciences et des arts. }\end{array}$ \\
\hline $\begin{array}{l}\text { Trouville, ou Detrouville, ou } \\
\text { Hermand de Trouville (J. B. } \\
\text { E.) [v. 1750-1813 ?], m.n.s }\end{array}$ & 3 mars 1791 & $\begin{array}{l}1791 \text { : signataire de l'acte de constitution initial de la SID. } \\
1791-1792 \text { : membre du Point central des arts et métiers où il est admis } \\
\text { le } 2 \text { octobre } 1791 \text { (dom. } 3 \text { faubourg Saint-Denis, près la caserne des } \\
\text { habillements). } \\
1791-1796 \text { : représentant de la SID au Bureau de consultation des } \\
\text { arts et métiers. } \\
1792 \text { : ingénieur, } 31 \text { faubourg Saint-Denis. } \\
1793 \text { : hydraulicien, } 66 \text { faubourg Saint-Denis. } \\
1798 \text { : ingénieur hydraulique, } 1398 \text { rue Notre-Dame des Champs, ou } \\
\text { aux Jeux gymniques. } \\
1810 \text { et } 1811 \text { : mention. }\end{array}$ \\
\hline Tugot & 1798 ou avant? & 1798 : orfèvre filigraniste \\
\hline Vachette, m.n.s. & $\begin{array}{l}29 \text { fructidor an VIII } \\
\text { [16 septembre 1800] }\end{array}$ & 1810 et 1811 : mention. \\
\hline Vannier, m.n.s. & $\begin{array}{l}16 \text { germinal an } \mathrm{VI} \\
{[5 \text { avril 1798] }}\end{array}$ & $\begin{array}{l}1798: \text { architecte, } 318 \text { rue du Jour. } \\
1810 \text { et } 1811: \text { mention. }\end{array}$ \\
\hline $\begin{array}{l}\text { Vasse (David) [av. } 1781 \text { - ap. } \\
\text { 1820], m.s }\end{array}$ & 3 avril 1806 & $\begin{array}{l}1810 \text { et } 1811 \text { : horloger, } 66 \text { rue Montmartre. } \\
\text { Membre de l'Athénée des arts. } \\
\text { Président de la SID pour } 1809 .\end{array}$ \\
\hline
\end{tabular}




\section{Inventeurs en Révolution}

\begin{tabular}{|c|c|c|}
\hline $\begin{array}{l}\text { Vausenville [Alexandre Hen- } \\
\text { ry Guillaume Le Rohbergherr } \\
\text { de, } 1722 \text { - ?] }\end{array}$ & 1791 & $\begin{array}{l}1791 \text { : signataire de l'acte de constitution initial de la SID. } \\
1798 \text { : astronome, } 122 \text { rue [Saint-] Jacques. }\end{array}$ \\
\hline Vegence & 1791 & 1791 : signataire de l'acte de constitution initial de la SID. \\
\hline $\begin{array}{l}\text { Vera, ou Verra (Charles), } \\
\text { m.n.s. }\end{array}$ & 6 mai 1791 & $\begin{array}{l}\text { 1791-1792: membre du Point central des arts et métiers (dom. La } \\
\text { Chapelle-Saint-Denis, chez le procureur syndic). } \\
1793 \text { : physicien, } 3 \text { rue Saint-Sauveur. } \\
1798 \text { : mécanicien, rue du Pot-de-Fer, vis-à-vis la rue de Mézières. } \\
1810 \text { et } 1811 \text { : mention. }\end{array}$ \\
\hline Viallon & 1798 ou avant? & 1798 : mécanicien, à la Bibliothèque du Panthéon. \\
\hline $\begin{array}{l}\text { Vincent [Abraham Aimé } \\
\text { Charles, av. } 1785 \text { - ap. } \\
\text { 1810] }\end{array}$ & $1792 ?$ & $\begin{array}{l}1792 \text { : horloger mécanicien, maison de Mme Vignon, rue Saint-Maur, } \\
\text { vis-à-vis la rue du Buisson Saint-Louis. } \\
1798 \text { : ingénieur, } 6 \text { rue [Saint-]Maur, section de Bondy. }\end{array}$ \\
\hline
\end{tabular}

